\title{
Design and Performance Study of Single and Multi-Layered Fractal Based Miniaturized Patch Antennas for 2.4 GHz Applications
}

\author{
Amiya Bhusana Sahoo (D), Guru Prasad Mishra (D), Biswa Binayak Mangaraj (D) \\ Department of Electronics and Telecommunication Engineering, Veer Surendra Sai University of Technology, \\ Burla, Sambalpur, Odisha, India \\ amiyabhusana@gmail.com,guruprasadmishra5@gmail.com,bbmangaraj@yahoo.co.in
}

\begin{abstract}
The design and characterization of single and multilayered miniaturized microstrip antennas resonating at $2.4 \mathrm{GHz}$ are proposed. The miniaturization is accomplished by fractal Defected Ground Structure (DGS). The DGS used for miniaturization is a Modified Minkowski Fractal DGS (MMFDGS). The proposed size reduction process with M-MFDGS follows the selection of the best antenna configuration and its design parameters through sensitivity analysis and pattern search optimization. Microstrip patch antennas with three different feeding mechanisms are considered here to validate the effect of DGS over the size reduction and performance improvement. Incorporating M-MFDGS in three antennas, the first one with microstrip line feed accomplishes a maximum patch area reduction of $70 \%$ among the three proposed structures with a gain of $1.43 \mathrm{dBi}$. Likewise, with a slightly higher dimension than the first structure, the second antenna with proximity-coupled feed achieves a higher gain (5.11 dBi) and bandwidth (110 MHz). Although the size reduction in the third antenna with aperture-coupled feed is a little less it has the highest gain $(5.91 \mathrm{dBi})$ among all the three. All three compact antennas are physically fabricated and the simulated results are validated with the measured results.
\end{abstract}

Index Terms - DGS, fractal, microstrip, Minkowski, patch

\section{INTRODUCTION}

Highly efficient transmitting and receiving antennas are needed to meet the requirements of modern antenna technology. Microstrip Patch Antenna (MPA) with its features such as low cost, lightweight, low profile, ease of integration, simple feeding, etc. has drawn the attention of many researchers. However, in this current era of portable communications, conventional half-wavelength MPAs are dramatically voluminous and need a whole new level of size reduction.

Numerous MPA miniaturization techniques have been examined and described in the literature. Some of the miniaturization techniques are creating metalized vias [1] between patch and ground plane, loading the patch inductively [2] by a cuboid ridge, using fractal edges [3], utilizing optimized antenna topology [4], making the use of metasurface, and meta-resonators [5], [6], etc. DGS concept is also used in literature for size reduction and to improve some performance parameters of planar microwave devices. Many DGS patterns, like dumbbell shape [7], circular-strips [8], triangular [9], E- 
shape [10], asymmetric L-shape [11], etc. are suggested for miniaturization of the MPAs, design of compact filters, and suppression of cross-polarization. However, in traditional DGS, maximum benefits can't be accomplished as it undergoes through a small slow-wave effect. The slow-wave effect can be further enhanced by effectively merging DGS with the fractal concept, which has been presented in our proposed work. The fractal concept is usually used for designing multiband [12] and wideband MPAs [13]. The composite word 'Fractal-DGS' means removing self-similar patterned shapes from the ground plane of an MPA. With the help of fractal DGS, improved size reduction is achieved for the conventional ones [14], [15]. Although in some literature, the Fractal-DGS concept is used for antenna miniaturization, a deep study is essential for maximum exploitation of the concept.

In this article, the effect of DGS is tested for three MPAs: one is a single-layered and the other two are multi-layered. By adjusting the indentation factors and the iteration orders of the fractal geometry, the compact MPAs along with superior performance parameters can be designed. Three different designs are considered here to find suitability in different applications. The first design is a singlelayered microstrip line fed MPA. The second and third designs are double layered MPAs with proximity-coupled feed and aperture-coupled feed, respectively. Using the M-MFDGS, the Design_1 MPA achieves the maximum size reduction of $70 \%$. At the same time, the second design and third design with M-MFDGS achieve a less size reduction than the first one but, with far greater performance characteristics. This article also performs a sensitivity analysis of M-MFDGS to select the best DGS patterns and their design parameters. Prototypes of all three proposed patch antennas are fabricated and their performances are measured. The entire design processes of the MPAs are described by an algorithm as shown below.

Algorithm:

Step 1: Select an application frequency $\left(f_{a}\right)$ for which the MPAs need to be designed

Step 2: Select a feeding technique (microstrip line feed, proximity-coupled feed, aperture-coupled feed, etc.) depending on the requirement (size, bandwidth, gain, etc.)

Step 3: Determine the design parameters of the MPAs using empirical formulae of the transmission line model of an MPA

Step 4: Design the MPAs in HFSS software and determine their frequency of resonance $\left(f_{r}\right)$

Step 5: Is $f_{r}=f_{a}$ ? If yes go to step 6 otherwise use parametric optimization and go to step 4

Step 6: Modify the MPA designs with fractal DGS of different indentations and iterations. Select the best among all the possible combinations

Step 7: Perform sensitivity analysis of the best fractal DGS to select its proper design parameters. Due to the application of the best fractal DGS, let the resonant frequency drops to $\left(f_{1}\right)$ from $\left(f_{r}\right)$.

Step 8: Let ' $\mathrm{m}$ ' is the ratio of $f_{r}$ and $f_{1}$. Determine a higher frequency $\left(f_{2}\right)$, such that $f_{2}=\mathrm{m} \times f_{r}$

Step 9: Determine the down-scaled version of design parameters for the fractal DGS at the frequency of $\boldsymbol{f}_{2}$ 
Step 10: Design the MPA with modified design parameters and determine its resonant frequency $\left(f_{r 1}\right)$

Step 11: Is $f_{r 1}=f_{a}$ ? If yes go to step 12 otherwise use pattern search optimization and go to step 10

Step 12: Make the physical design of the MPA and do the measurement

This work disseminates a simple and effective methodology for designing compact MPAs. The entire article can be summarized in the following manner. Section I provides a brief introduction to different antenna miniaturization techniques available in the literature and our proposed methodology for antenna miniaturization. The conventional MPAs, their feeding techniques, fractal geometry, and their modifications are described in Section II. This section also describes the adaption of sensitivity analysis for finding superior DGS. Section III describes the design of compact patch antennas resonating at $2.4 \mathrm{GHz}$ using the best DGS structures from the previous section. The results of simulated MPAs, the results of the fabricated MPAs, and a comparative study of proposed MPA with the MPAs available in the literature are described in section IV. Section V provides concluding remarks.

\section{Design of Conventional MPAs and Modified Fractal DGS}

\section{A. Conventional MPAs}

For ease of analysis, three conventional patch antennas denoted as Design_1 (with microstrip line feeding), Design_2 (with proximity-coupled feeding), and Design_3 (with aperture-coupled feeding) are considered and they are shown in Fig. 1. In Design_1, the substrate material used is FR4_epoxy with a relative permittivity $\left(\varepsilon_{r}\right)$, relative permeability $\left(\mu_{r}\right)$, and a dielectric loss tangent (tan $\delta$ ) of 4.4, 1, and 0.018, respectively. The Design_2 and Design_3, utilize this FR4 epoxy as the lower substrate and Rogers RT/Duroid 5880 as the upper substrate with a $\varepsilon_{r}$ of 2.2, $\mu_{r}$ of 1 , and a $\tan \delta$ of 0.0009 , respectively. The three conventional MPAs are resonating at $2.4 \mathrm{GHz}$. The dimensions of the antennas are calculated using the empirical formulae of the transmission line model of an MPA [16]. The dimensions of the three conventional MPAS are mentioned in Table I.

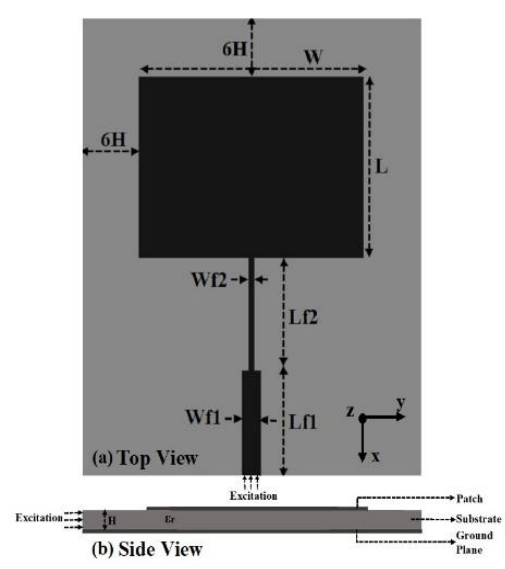

(i)

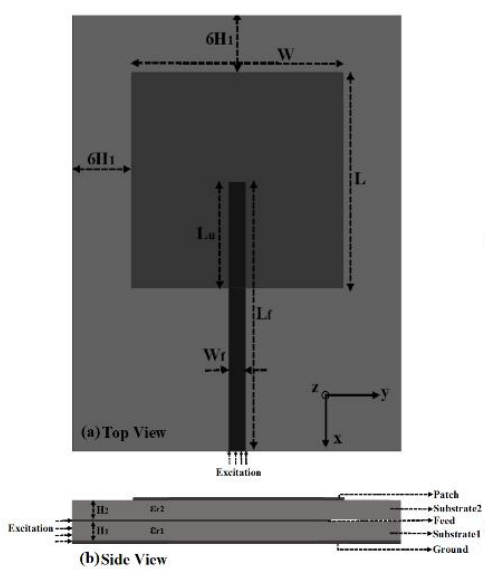

(ii)

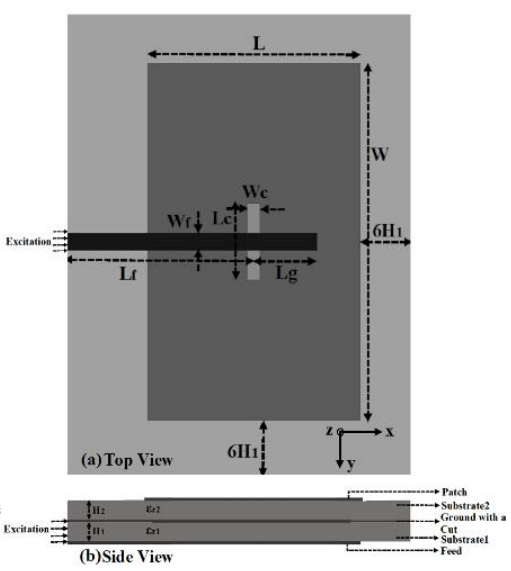

(iii)

Fig. 1. Conventional MPAs (i) Microstrip line fed MPA (ii) Proximity-coupled fed MPA (iii) Aperture-coupled fed MPA

Brazilian Microwave and Optoelectronics Society-SBMO Brazilian Society of Electromagnetism-SBMag received 20 Dec 2020; for review 27 Dec 2020; accepted 9 Mar 2021 (C) 2021 SBMO/SBMag (cc) BY ISSN 2179-1074 
TABLe I. The Dimensions of CONVENTIONAL MPAS

\begin{tabular}{|c|c|c|c|c|c|}
\hline \multicolumn{2}{|c|}{ Design1_MPA } & \multicolumn{2}{|c|}{ Design2_MPA } & \multicolumn{2}{|c|}{ Design3_MPA } \\
\hline $\begin{array}{c}\text { Design } \\
\text { Variables }\end{array}$ & $\begin{array}{l}\text { Value } \\
(\mathrm{mm})\end{array}$ & $\begin{array}{c}\text { Design } \\
\text { Variables }\end{array}$ & $\begin{array}{l}\text { Value } \\
(\mathrm{mm})\end{array}$ & $\begin{array}{c}\text { Design } \\
\text { Variables }\end{array}$ & $\begin{array}{l}\text { Value } \\
(\mathrm{mm})\end{array}$ \\
\hline $\mathrm{H}$ & 1.6 & H1 & 1.6 & H1 & 1.6 \\
\hline $\mathrm{L}$ & 28.05 & $\mathrm{H} 2$ & 1.5 & $\mathrm{H} 2$ & 1.5 \\
\hline Lf1 & 16.59 & $\mathrm{~L}$ & 32.96 & $\mathrm{~L}$ & 37 \\
\hline Lf2 & 17.61 & $\mathrm{Lu}$ & 16.94 & Lc & 13.38 \\
\hline W & 36.86 & Lf & 43.05 & $\mathrm{Lg}$ & 11.35 \\
\hline Wf1 & 3.059 & W & 35.2 & Lf & 34.38 \\
\hline \multirow[t]{3}{*}{ Wf2 } & 0.9 & Wf & 2.801 & W & 62.74 \\
\hline & & & & Wc & 2.3 \\
\hline & & & & Wf & 3.059 \\
\hline
\end{tabular}

The fractal DGS are applied with different indentations and iterations to these conventional MPAs. Due to the application of fractal DGS, there is a drop in resonant frequency. It is analyzed carefully and the best among all the possible combinations of Defected Ground Structures is selected. The detailed procedure for antenna miniaturization is discussed in the next section.

\section{B. Fractal DGS Geometry and Its Modifications}

As discussed earlier, a simple etched structure of the DGS geometry introduces additional capacitance and inductance. But the slow-wave effect due to this additional capacitance and inductance is not enough. Therefore, these traditional DGS don't give a satisfactory result. On the other hand, by combining DGS with modified fractal geometries, MPA's resonant frequency can be reduced further by a large amount. Since the frequency of resonance is lowered and the physical size of the MPA remains intact, a reduction in the size is said to be accomplished. The generation of a fractal shape depends on two parameters: indentation factor and iteration order. The Minkowski Fractal DGS (MFDGS) and Modified Minkowski Fractal DGS (M-MFDGS) are shown in Fig. 2.

In this article, the MFDGS [13] and the M-MFDGS are denoted as the Type1 Minkowski structure and Type2 Minkowski structure, respectively. The indentation is inward in the MFDGS structure and outward in the M-MFDGS structure. The M-MFDGS structure is deliberately adopted to attain extra electrical areas so that more equivalent inductance and capacitance values are obtained than the MFDGS. Initially, a simple DGS (dumbbell-shaped) is used in the MPAs for miniaturization. Later, the simple DGS structure is modified by applying the first iteration of Type1 fractal and Type2 fractal separately. Further, these DGS are modified by using the second iteration of the Type1 and Type2 fractals. 


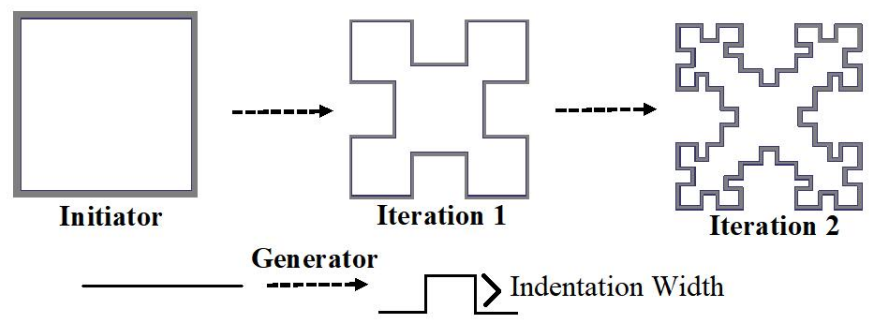

(a) Type1 Minkowski

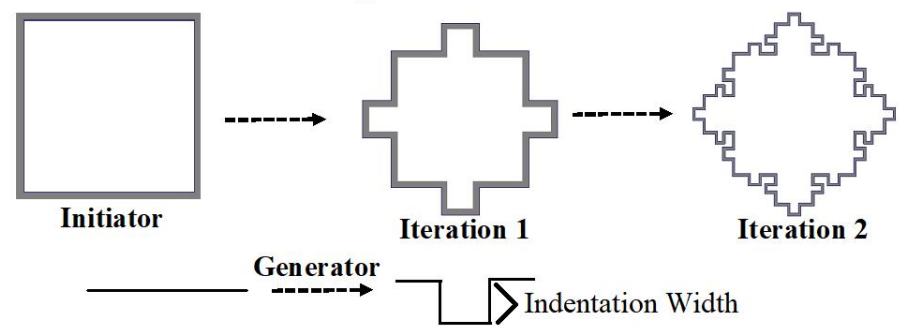

(b) Type2 Minkowski

Fig. 2. (a) Type1 Minkowski fractal and, (b) Type2 Minkowski fractal with different iterations

Fig. 3 (i) depicts the different possibilities of fractal-DGS patterns applied to an MPA. Fig. 3 (ii) represents another design which includes a rectangular shape slot present in the ground structure. This slot remains constant and the same ten cases as discussed in Fig. 3 (i) are considered for this design. The dimensions of the plane DGS as shown in Fig. 3 (i) and (ii) are $\mathrm{D}=5.83 \mathrm{~mm}, \mathrm{~S}=2.33 \mathrm{~mm}, \mathrm{~W} 1=$ $4.67 \mathrm{~mm}, \mathrm{~L} 1=4.67 \mathrm{~mm}$, and $\mathrm{a}=4.67 \mathrm{~mm}$. The width of wire for wire DGS is $0.5 \mathrm{~mm}$.

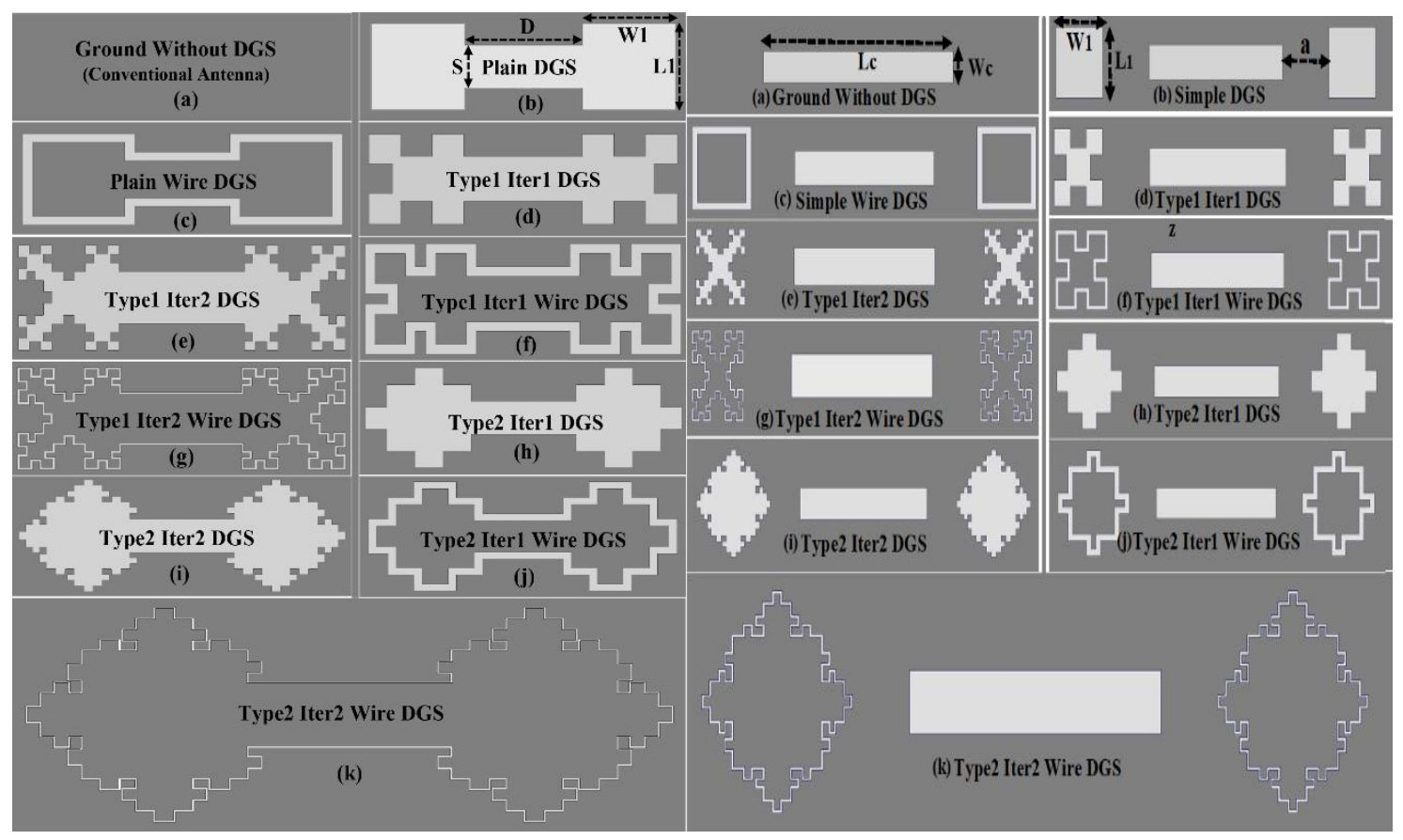

(i)

(ii)

Fig. 3. Different Fractal-DGS along with their wired versions for $1^{\text {st }}$ and $2^{\text {nd }}$ iterations: (i) For Design_1 and Design_2 MPA (ii) For Design_3 MPA [Unetched Ground plane - Grey color, Etched portion - white color]. 
Among the above prescribed ten DGS patterns, half of the cases are the wired equivalent structure of the other halves. In the wired version of DGS, only the border with a certain width is engraved out while other portions of the ground plane remain intact as shown in Fig. 3. These unremoved areas facilitate the electric field to build up across the ground structure and as a result of this effective capacitance of the model increases substantially [17]. Since the return current in the square areas surrounding the etched boundary of the ground plane remains the same, the effective inductance almost remains the same. The DGS model as shown in Fig. 3 (i)-c provides significant miniaturization than the conventional DGS model as shown in Fig. 3 (i)-b [17]. Also, the MPA provides improved performance by controlling the gap between the boundary lines of wired DGS in both $\mathrm{x}$ and $\mathrm{y}$ directions. The Design_1, Design_2, and Design_3 as shown in Fig. 1, embedded with these ten different DGS patterns are simulated using HFSS software. The performances of these three designs with all the ten cases are mentioned in Table II. It is observed from the table that in Design_1, 2, and 3, with the ten DGS models, there is a decrease in resonant frequency with respect to their plain ground plane without DGS. Between Type1 (MFDGS) and Type2 (M-MFDGS), Type2 provides an improved size reduction than Type1 in all the two iterations. Additionally, the wire DGS has a better reduction in the frequency of resonance as compared to their corresponding simple DGS structure. In the case of Design_1 MPA, the Type2 Iter1 wire DGS and Type2 Iter2 DGS have a maximum resonant frequency drop from $2.4 \mathrm{GHz}$ to $1.97 \mathrm{GHz}$ as mentioned in Table II. Overall the Type2 Iter1 wire DGS provides better impedance matching and radiation characteristics among all the DGS structures for Design_1 MPA. Therefore, Type2 Iter1 wire DGS is selected for Design_1 MPA. The maximum drop of the frequency of resonance from $2.4 \mathrm{GHz}$ to $2.08 \mathrm{GHz}$ occurs in the case of Type 2 Iter2 wire DGS for Design_2 MPA. Making a trade-off among bandwidth, gain, and resonant frequency, the Type2 Iter1 wire DGS is chosen for Design_2 having the highest bandwidth of 80 $\mathrm{MHz}$, a gain of $5.34 \mathrm{dBi}$, and the second-lowest resonant frequency of $2.12 \mathrm{GHz}$ as mentioned in Table II. Likewise, in the case of Design_3, with a $50 \mathrm{MHz}$ bandwidth and $7.65 \mathrm{dBi}$ peak gain, Type2 Iter1 has opted as best among all four DGS having the same lower resonant frequency of $2.344 \mathrm{GHz}$ as mentioned in Table II. In this table, S11 (dB) represents the reflection coefficient in $\mathrm{dB}$.

Using different types of DGS models, decrement in $f_{r}$ is observed. Still, there is a scope for improvisation in the amount of reduction of $f_{r}$. Therefore, a detailed study is carried out analyzing the different patterns of DGS and their design parameters to accomplish the antenna miniaturization to a greater extent. Based on a sensitivity analysis, several key factors are described in the following section to achieve a highly compact design. 

DOI: http://dx.doi.org/10.1590/2179-10742021v20i21165

Table II. Comparison of Simulation Results of Ten DGS Patterns ApPlied to Three Different Designs

\begin{tabular}{|c|c|c|c|c|c|c|c|c|c|c|c|c|}
\hline \multirow{3}{*}{$\begin{array}{l}\text { DGS } \\
\text { Types }\end{array}$} & \multicolumn{4}{|c|}{ Design_1 MPA } & \multicolumn{4}{|c|}{ Design_2 MPA } & \multicolumn{4}{|c|}{ Design_3 MPA } \\
\hline & \multirow{2}{*}{$\begin{array}{c}\mathbf{f}_{\mathbf{r}}(\mathbf{G H z}) / \\
\text { BW (MHz) }\end{array}$} & \multirow{2}{*}{ S11 (dB) } & \multicolumn{2}{|c|}{ Gain (dBi) } & \multirow{2}{*}{$\begin{array}{c}\mathbf{f}_{\mathbf{r}}(\mathbf{G H z}) / \\
\text { BW (MHz) }\end{array}$} & \multirow{2}{*}{ S11 (dB) } & \multicolumn{2}{|c|}{ Gain (dBi) } & \multirow{2}{*}{$\begin{array}{c}\mathbf{f}_{\mathbf{r}}(\mathbf{G H z}) / \\
\text { BW (MHz) }\end{array}$} & \multirow{2}{*}{ S11 (dB) } & \multicolumn{2}{|c|}{ Gain (dBi) } \\
\hline & & & E -Plan & I -Plan & & & E -Plan & I -Plan & & & E -PI & H -Plane \\
\hline $\begin{array}{l}\text { Without } \\
\text { DGS }\end{array}$ & $\begin{array}{l}2.4 \\
50\end{array}$ & -17 & 3.22 & 2.87 & $\begin{array}{l}2.4 \\
80\end{array}$ & -34.49 & 5.97 & 5.91 & $\begin{array}{c}2.40 \\
60\end{array}$ & -35.73 & 7.64 & 7.64 \\
\hline $\begin{array}{l}\text { Plain } \\
\text { DGS }\end{array}$ & $\begin{array}{c}2.058 \\
50\end{array}$ & -23.32 & 2.58 & 2.43 & $\begin{array}{l}2.2 \\
70\end{array}$ & -23.39 & 5.48 & 5.44 & $\begin{array}{c}2.366 \\
50\end{array}$ & -30.49 & 7.64 & 7.64 \\
\hline $\begin{array}{c}\text { Plain } \\
\text { DGS wire }\end{array}$ & $\begin{array}{c}2.036 \\
60\end{array}$ & -20.09 & 2.48 & 2.36 & $\begin{array}{c}2.19 \\
80\end{array}$ & -23.68 & 5.48 & 5.44 & $\begin{array}{c}2.344 \\
50\end{array}$ & -28.40 & 7.61 & 7.61 \\
\hline $\begin{array}{c}\text { Type1 } \\
\text { Iter1 }\end{array}$ & $\begin{array}{c}2.08 \\
50\end{array}$ & -22.59 & 2.65 & 2.51 & $\begin{array}{c}2.212 \\
80\end{array}$ & -25.10 & 5.60 & 5.55 & $\begin{array}{c}2.366 \\
60\end{array}$ & -26.49 & 7.65 & 7.65 \\
\hline $\begin{array}{l}\text { Type1 } \\
\text { Iter2 }\end{array}$ & $\begin{array}{c}2.124 \\
50\end{array}$ & -17.46 & 2.67 & 2.49 & $\begin{array}{c}2.234 \\
80\end{array}$ & -28.86 & 5.66 & 5.61 & $\begin{array}{c}2.366 \\
50\end{array}$ & -20.31 & 7.71 & 7.71 \\
\hline $\begin{array}{c}\text { Type1 } \\
\text { Iter1 wire }\end{array}$ & $\begin{array}{c}2.014 \\
50\end{array}$ & -17.35 & 2.44 & 2.30 & $\begin{array}{c}2.146 \\
80\end{array}$ & -27.88 & 5.42 & 5.39 & $\begin{array}{c}2.366 \\
60\end{array}$ & -22.29 & 7.64 & 7.64 \\
\hline $\begin{array}{l}\text { Type1 } \\
\text { Iter2 wire }\end{array}$ & $\begin{array}{c}2.058 \\
40\end{array}$ & -22.84 & 2.47 & 2.30 & $\begin{array}{c}2.19 \\
70\end{array}$ & -22.09 & 5.45 & 5.42 & $\begin{array}{c}2.366 \\
50\end{array}$ & -30.91 & 7.65 & 7.65 \\
\hline $\begin{array}{l}\text { Type2 } \\
\text { Iter1 }\end{array}$ & $\begin{array}{c}2.014 \\
60\end{array}$ & -22.62 & 2.46 & 2.32 & $\begin{array}{c}2.168 \\
80\end{array}$ & -20.89 & 5.45 & 5.41 & $\begin{array}{c}2.344 \\
50\end{array}$ & -27.52 & 7.65 & 7.65 \\
\hline $\begin{array}{l}\text { Type2 } \\
\text { Iter2 }\end{array}$ & $\begin{array}{c}1.97 \\
60\end{array}$ & -17.55 & 2.43 & 2.33 & $\begin{array}{c}2.146 \\
70\end{array}$ & -19.61 & 5.45 & 5.42 & $\begin{array}{c}2.344 \\
50\end{array}$ & -19.62 & 7.64 & 7.64 \\
\hline $\begin{array}{l}\text { Type2 } \\
\text { Iter1 } \\
\text { wire }\end{array}$ & $\begin{array}{c}1.97 \\
50\end{array}$ & -32.66 & 2.45 & 2.35 & $\begin{array}{c}2.124 \\
80\end{array}$ & -27.77 & 5.34 & 5.31 & $\begin{array}{c}2.344 \\
60\end{array}$ & -19.88 & 7.57 & 7.57 \\
\hline $\begin{array}{l}\text { Type } 2 \\
\text { Iter2 wire }\end{array}$ & $\begin{array}{c}2.014 \\
50\end{array}$ & -18.73 & 2.31 & 2.17 & $\begin{array}{c}2.08 \\
70\end{array}$ & -24.24 & 5.07 & 5.06 & $\begin{array}{c}2.344 \\
50\end{array}$ & -19.14 & 7.61 & 7.61 \\
\hline
\end{tabular}

\section{Sensitivity Analysis}

DGS provides extra lumped inductance and capacitance in microstrip patch antennas. The inductance value is increased due to an increase in etched areas. Similarly, the increase in capacitance is a result of the increase of distance between heads of the DGS models [7]. As discussed in the previous section, the use of different fractal DGS and their iterations, don't provide a significant amount of size reduction of an MPA. Therefore, for further size reduction of the MPAs, the impact of design parameters of DGS is reinvestigated. The reinvestigation comprises a sensitivity analysis. The sensitivity analysis is a study of resonant frequency variation with change in the design parameters of DGS such as L1, W1, D, S, etc. (as mentioned in Fig. 3). The variation of resonant frequency over the variation of design parameters can be analyzed using sensitivity analysis in HFSS software [18]. In this analysis, for a small variation of design parameters, the change in resonant frequency is obtained. Using curve fitting, the performance curves for individual parameters are plotted as shown in Fig. 4, Fig. 5, and Fig. 6. The parameters considered for sensitivity analysis of Design_1 MPA and Design_2 MPA are 'L1', 'W1', 'S1', and 'D' as shown in Fig. 4 and Fig. 5, respectively. For Design_3, 'L1', 'W1', and 'a' are taken into account for sensitivity analysis as shown in Fig. 6. As discussed earlier, the Type2 Iter1 wire fractal DGS gives overall good performance for Design_1 and Design_2; Type2 Iter1 fractal DGS gives overall good performance for Design_3. The dimensions of these three MPA designs are further reduced using this sensitivity analysis. 


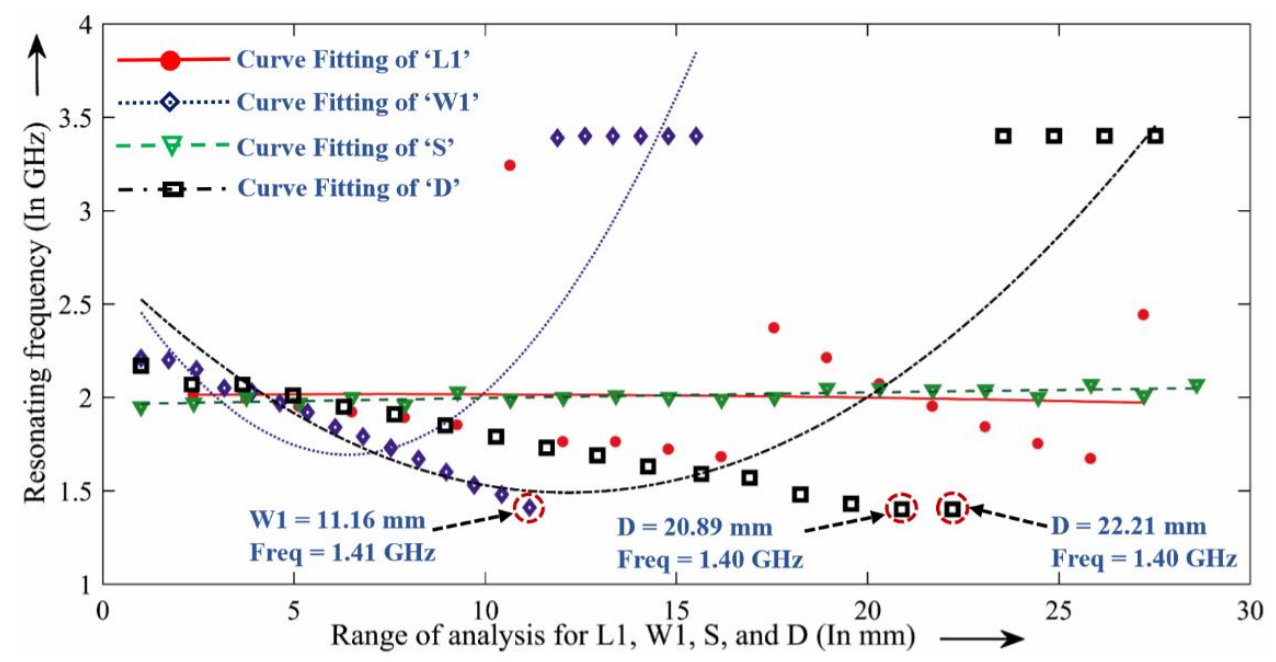

Fig. 4. Design_1 antenna: Resonating frequency versus design parameters for Type2 Iter1 wireframe DGS.

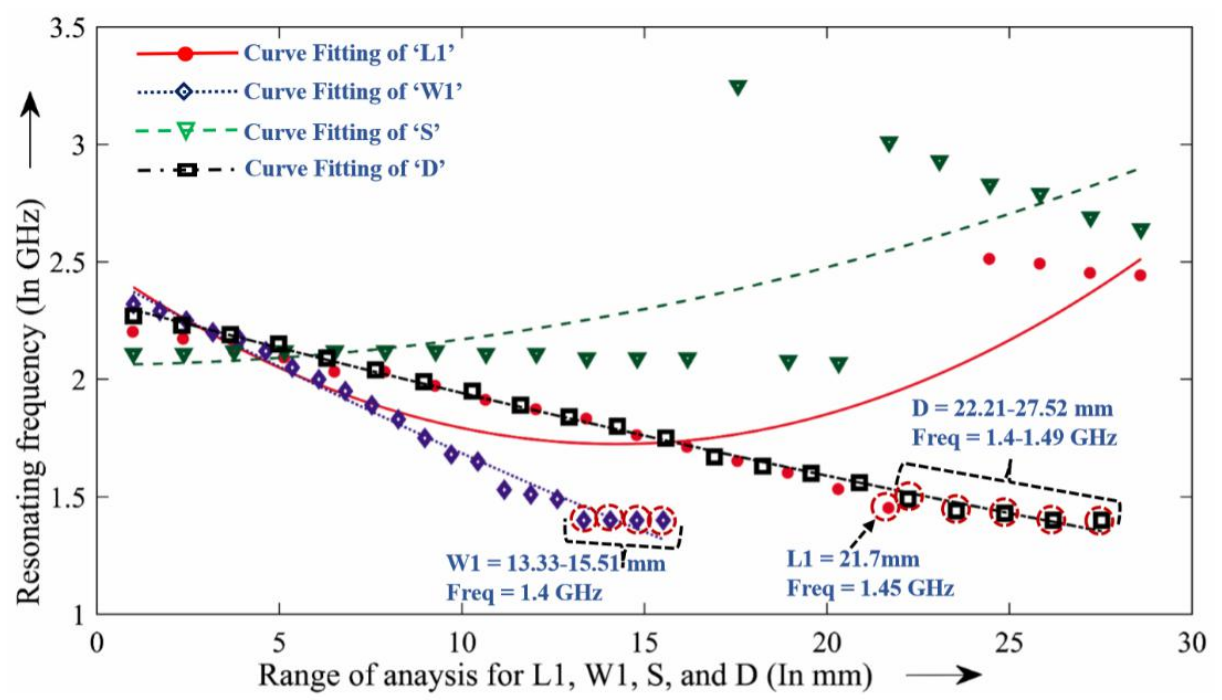

Fig. 5. Design_2 antenna: Resonating frequency versus design parameters for Type2 Iter1 wireframe DGS.

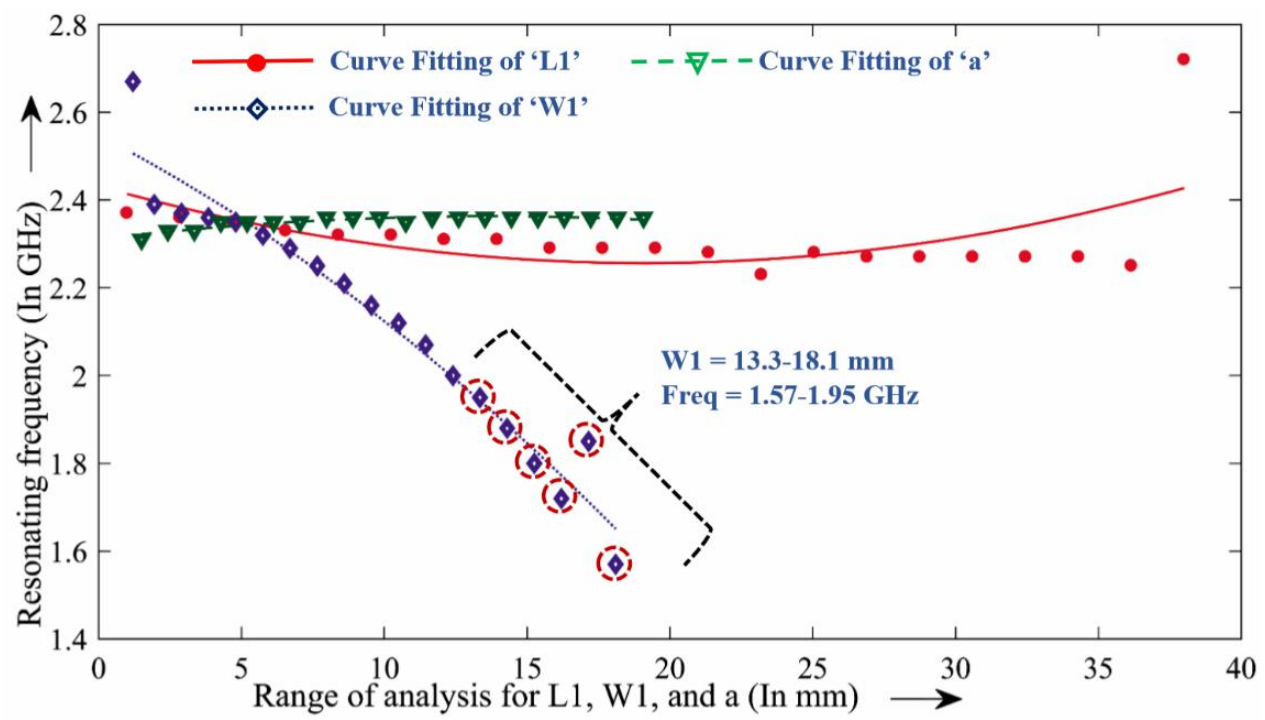

Fig. 6. Design_3 antenna: Resonating frequency versus design parameters for Type2 Iter1 fractal DGS. 
Fig. 4 and Fig. 5 show that the parameter 'W1' and 'D' have more influence than 'L1' and ' $S$ ' for the reduction in frequency for Design_1 and Design_2. Fig. 6 shows that the parameter 'W1' has more influence than 'L1' and ' $\mathrm{a}$ ' for the reduction in frequency for Design_3. The lower and upper limits of frequency are set to $1.4 \mathrm{GHz}$ and $3.4 \mathrm{GHz}$ for sensitivity analysis of Design_1 MPA and Design_2 MPA, respectively. Similarly, for Design_3 MPA, the lower and upper limits of frequency are set to $1.6 \mathrm{GHz}$ and $3.6 \mathrm{GHz}$, respectively. For some values of the parameters 'W1' / 'D', the frequency reduction attains the lower frequency limit and a further decrease in resonant frequency is expected. Therefore, at a time effect of variation of one parameter is studied i.e. one parameter is varied and at that time other parameters are kept to their initial values (mentioned in Fig. 3). For example, when W1 is only varied with other parameters (L1, S, and D) are kept constant. It is observed that in $\mathrm{W} 1$ variation, at $\mathrm{W} 1=11.16 \mathrm{~mm}$ the resonant frequency drops to $1.41 \mathrm{GHz}$. Similarly, when $\mathrm{D}$ is only varied, at $\mathrm{D}=20.89 \mathrm{~mm} / 22.21 \mathrm{~mm}$ the frequency drops to $1.40 \mathrm{GHz}$. These cases are depicted in Fig. 4. However, with L1, W1, S, and D values $4.67 \mathrm{~mm}, 4.67 \mathrm{~mm}, 2.33 \mathrm{~mm}$, and $20.89 \mathrm{~mm}$ respectively, the design is considered to be best for Design_1. In this case, the antenna has good performance parameters such as lower resonant frequency, substantial gain, and excellent impedance matching of $1.38 \mathrm{GHz}, 3.27 \mathrm{dBi}$, and $49+\mathrm{j} 11 \Omega$, respectively. Likewise, in Design_2, W1 with a range of $13.3378 \mathrm{~mm}$ to $15.5150 \mathrm{~mm}$, L1 with $21.7 \mathrm{~mm}$, and D with a range of $22.216 \mathrm{~mm}$ to $27.520 \mathrm{~mm}$ show a maximum reduction in the frequency of resonance as depicted in Fig. 5. The Design_2 MPA resonating at $2.4 \mathrm{GHz}$ resonates at $1.28 \mathrm{GHz}$ for $\mathrm{W} 1=14.7892 \mathrm{~mm}$. Although the frequency reduction is massive, the antenna has poor performance parameters. Therefore, a trade-off is made between size and performance. For Design_2, with W1 $=6.806 \mathrm{~mm}$, the bandwidth and gain are achieved to be $80 \mathrm{MHz}$ and $4.75 \mathrm{dBi}$, respectively. Similarly, for Design_3, from Fig. 6 it is observed that for W1 equals $13.35 \mathrm{~mm}$, the resonant frequency is $1.95 \mathrm{GHz}$. As W1 increases, the frequency decreases. At $\mathrm{W} 1$ equals to $18.10 \mathrm{~mm}$ the resonant frequency drops to $1.57 \mathrm{GHz}$ with degraded performance. Making a trade-off between performance and frequency reduction, the W1 is chosen as $14.3 \mathrm{~mm}$ for the Design_3 MPA. This MPA has the gain and the bandwidth of $5.77 \mathrm{dBi}$ and $60 \mathrm{MHz}$, respectively.

The summary of the best design parameters chosen for the three MPA designs is as follows. Design_1: $(\mathrm{L} 1, \mathrm{~W} 1, \mathrm{~S}, \mathrm{D})=(4.67 \mathrm{~mm}, 4.67 \mathrm{~mm}, 2.33 \mathrm{~mm}, 20.89 \mathrm{~mm})$ : Design_2: $(\mathrm{L} 1, \mathrm{~W} 1, \mathrm{~S}, \mathrm{D})=$ $(4.67 \mathrm{~mm}, 6.806 \mathrm{~mm}, 2.33 \mathrm{~mm}, 5.83 \mathrm{~mm})$ and Design_3: $(\mathrm{L} 1, \mathrm{~W} 1, \mathrm{a})=(4.67 \mathrm{~mm}, 14.3 \mathrm{~mm}, 4.67$ $\mathrm{mm})$. In the next section, MPAs designed utilizing the scaled dimension of these DGS patterns, resonating exactly at $2.4 \mathrm{GHz}$ are discussed.

\section{Compact Patch Antenna Design and Analysis}

The proposed methodology concentrates on discovering the best DGS patterns and their appropriate design parameters to achieve a substantial frequency reduction in the MPA designs. The primary objective of the article is to design the MPAs at the ISM band of $2.4 \mathrm{GHz}$. Therefore, 
first, the three MPAs are designed at higher frequencies so that the dimensions of the MPAs are small. Then the scaled versions of the best fractal DGS obtained in the last section are applied on these MPAs to reduce their resonant frequencies to $2.4 \mathrm{GHz}$. The proposed methodology requires the accurate calculation of the higher frequency, design of the MPA at this frequency, and the design of appropriate fractal DGS structure for this MPA.

From sensitivity analysis, it is found that Type2 Iter1 wire DGS provides a drop of resonant frequency from $2.4 \mathrm{GHz}$ to $1.38 \mathrm{GHz}$ for Design_1 MPA. The corresponding wavelength increases by $42.49 \%$. In other words, it can be said that the MPA is operating at $1.38 \mathrm{GHz}$ with a wavelength of $42.49 \%$ lower than its actual wavelength. Applying the same logic, for designing an MPA operating at $2.4 \mathrm{GHz}$, another MPA is to be designed at a wavelength $42.49 \%$ lower than the actual wavelength of $2.4 \mathrm{GHz}$. Therefore, an MPA with a resonant frequency of $4.16 \mathrm{GHz}\left(\lambda_{0}=72.26 \mathrm{~mm}\right)$ is to be designed. To design the MPA resonating at $4.16 \mathrm{GHz}$, the identical substrate FR4_epoxy is used as that of Design_1 with the design parameters downscaled as that of the MPA resonating at 2.4 GHz. The design parameters of this MPA (L, W, Lf1, Wf1, Lf2, Wf2, H) resonating at $4.16 \mathrm{GHz}$ are found to be (15.88 mm, $19.11 \mathrm{~mm}, 9.56 \mathrm{~mm}, 3.059 \mathrm{~mm}, 10.11 \mathrm{~mm}, 0.4288 \mathrm{~mm}, 1.6 \mathrm{~mm})$, respectively. The best design parameters of the M-MFDGS obtained for Design_1 through sensitive analysis are $\mathrm{L} 1=0.03736 \lambda_{0}(4.67 \mathrm{~mm}), \mathrm{W} 1=0.03736 \lambda_{0}(4.67 \mathrm{~mm}), \mathrm{S}=0.01864 \lambda_{0}(2.33 \mathrm{~mm})$, and $\mathrm{D}=0.16712 \lambda_{0}(20.89 \mathrm{~mm})$, where $\lambda_{0}=125 \mathrm{~mm}$. For the $f_{r}=4.16 \mathrm{GHz}$ i.e. $\lambda_{0}=72.26 \mathrm{~mm}$ the corresponding design parameters will be $\mathrm{L} 1=0.03736 \lambda_{0}(2.694 \mathrm{~mm}), \mathrm{W} 1=0.03736 \lambda_{0}(2.694 \mathrm{~mm})$, $\mathrm{S}=0.01864 \lambda_{0}(1.344 \mathrm{~mm})$, and $\mathrm{D}=0.16712 \lambda_{0}(12.034 \mathrm{~mm})$. The same technique is used for Design_2 and Design_3 MPAs. From sensitivity analysis, the maximum frequency drop is observed from $2.4 \mathrm{GHz}$ to $1.94 \mathrm{GHz}$ for Design_2 MPA using Type2 Iter1 wire fractal DGS. By doing a similar calculation as that of Design_1, a new MPA which has a resonant frequency of $2.97 \mathrm{GHz}\left(\lambda_{0}\right.$ $=101 \mathrm{~mm}$, which is $19.16 \%$ lower than $\lambda_{0}=125 \mathrm{~mm}$ ) is to be designed for Design_2 MPA. The scaled design parameters for the Design_2 MPA and its corresponding DGS at $f_{r}=2.97 \mathrm{GHz}$ are, L $=27.66 \mathrm{~mm}, \mathrm{~W}=27.66 \mathrm{~mm}, \mathrm{Lu}=13.61 \mathrm{~mm}, \mathrm{Lf}=36.42 \mathrm{~mm}, \mathrm{Wf}=2.787 \mathrm{~mm}, \mathrm{H} 1=1.6 \mathrm{~mm}, \mathrm{H} 2=$ $1.5 \mathrm{~mm}, \mathrm{~L} 1=3.77 \mathrm{~mm}, \mathrm{~W} 1=5.499 \mathrm{~mm}, \mathrm{~S}=1.88 \mathrm{~mm}$, and $\mathrm{D}=4.71 \mathrm{~mm}$. Similarly from sensitivity analysis, the maximum frequency drop is observed from $2.4 \mathrm{GHz}$ to $1.88 \mathrm{GHz}$ for Design_3 MPA using Type2 Iter1 fractal DGS. Repeating the same procedure, the new MPA for Design_3 needs to be designed to resonate at $3.052 \mathrm{GHz}$ with $\lambda_{0}=98.29 \mathrm{~mm}$ which is $21.38 \%$ lower than $\lambda_{0}=125 \mathrm{~mm}$. The scaled design parameters for the Design_3 MPA and its corresponding DGS (L, W, Lc, Wc, Lg, Lf, Wf, H1, H2, L1, W1, and a) resonating at $3.052 \mathrm{GHz}$ are found to be $(27.5 \mathrm{~mm}, 49.11 \mathrm{~mm}, 11.6$ $\mathrm{mm}, 0.9823 \mathrm{~mm}, 8.628 \mathrm{~mm}, 26.91 \mathrm{~mm}, 3.059 \mathrm{~mm}, 1.6 \mathrm{~mm}, 1.5 \mathrm{~mm}, 3.67 \mathrm{~mm}, 11.24 \mathrm{~mm}$, and 3.67 $\mathrm{mm})$, respectively. The substrate materials remain the same for these Design_2 and Design_3 MPAs as that of their corresponding conventional designs without DGS.

The three MPAs are designed in ANSYS HFSS software with the calculated design parameters. A slight deviation in the desired frequency is observed because of the rounding off made in the Brazilian Microwave and Optoelectronics Society-SBMO received 20 Dec 2020; for review 27 Dec 2020 ; accepted 9 Mar 2021 
design parameters. The resonant frequencies are found to be $2.464 \mathrm{GHz}, 2.4 \mathrm{GHz}$, and $2.528 \mathrm{GHz}$ for the three MPAs, respectively. There are several optimization algorithms $[19,20]$ that can be used to obtain the required design parameters to resonate the MPAs exactly at $2.4 \mathrm{GHz}$. Here the pattern search optimization algorithm inbuilt in HFSS is applied to obtain the necessary parameters of the MPAs. The objective function of the algorithm is minimized for optimization. The antenna parameters such as S11, gain, radiation efficiency, etc. are enhanced using this pattern search optimization. The resonant frequency of Design_1 MPA is brought back to $2.4 \mathrm{GHz}$ from 2.464 GHz. The corresponding design parameters for Design_1 are L $=16.34 \mathrm{~mm}$ and L1 $=2.9634 \mathrm{~mm}$. Similarly, the resonant frequency of Design_3 MPA is brought back to $2.4 \mathrm{GHz}$ from $2.528 \mathrm{GHz}$. The corresponding design parameters of Design_3 MPA are L $=29.5 \mathrm{~mm}, \mathrm{Lc}=13.05 \mathrm{~mm}$, and W1 $=11.7 \mathrm{~mm}$. Since Design_2 MPA is resonating exactly at $2.4 \mathrm{GHz}$ with good performance parameters, no optimization is performed. The summary of all the design parameters of three compact MPAs post optimization is listed in Table III.

TABle III. Design Parameters of The Three Compact MPAs

\begin{tabular}{|c|c|c|c|c|c|}
\hline \multicolumn{2}{|c|}{ Design1_MPA } & \multicolumn{2}{|c|}{ Design2_MPA } & \multicolumn{2}{|c|}{ Design3_MPA } \\
\hline $\begin{array}{c}\text { Design } \\
\text { Variables }\end{array}$ & $\begin{array}{l}\text { Value } \\
(\mathrm{mm})\end{array}$ & $\begin{array}{c}\text { Design } \\
\text { Variables }\end{array}$ & $\begin{array}{l}\text { Value } \\
(\mathrm{mm})\end{array}$ & $\begin{array}{c}\text { Design } \\
\text { Variables }\end{array}$ & $\begin{array}{l}\text { Value } \\
(\mathbf{m m})\end{array}$ \\
\hline $\mathrm{L}$ & 16.34 & $\mathrm{~L}$ & 27.66 & $\mathrm{~L}$ & 29.5 \\
\hline W & 19.11 & W & 27.66 & W & 49.11 \\
\hline Lf1 & 9.56 & $\mathrm{Lu}$ & 13.61 & $\mathrm{Lc}$ & 13.05 \\
\hline Lf2 & 10.11 & Lf & 36.42 & $\mathrm{Wc}$ & 0.982 \\
\hline Wf1 & 3.059 & Wf & 2.787 & $\mathrm{Lg}$ & 8.628 \\
\hline Wf2 & 0.4288 & $\mathrm{H} 1$ & 1.6 & $\mathrm{Lf}$ & 26.91 \\
\hline $\mathrm{H}$ & 1.6 & $\mathrm{H} 2$ & 1.5 & Wf & 3.059 \\
\hline L1 & 2.9634 & L1 & 3.77 & H1 & 1.6 \\
\hline W1 & 2.694 & W1 & 5.499 & $\mathrm{H} 2$ & 1.5 \\
\hline $\mathrm{S}$ & 1.344 & $\mathrm{~S}$ & 1.88 & L1 & 3.67 \\
\hline $\mathrm{D}$ & 12.034 & $\mathrm{D}$ & 4.71 & W1 & 11.7 \\
\hline & & & & $\mathrm{a}$ & 3.67 \\
\hline
\end{tabular}

After optimized parameters are obtained, the three compact MPAs and only the microstrip line fed conventional MPA are physically fabricated. These fabricated MPAs are shown in Fig. 7. In Design_1, the patch area has reduced by $70 \%$ from $0.29 \lambda_{0} \times 0.22 \lambda_{0}$ (Conventional microstrip line edge feed MPA) to $0.15 \lambda_{0} \times 0.13 \lambda_{0}$ (proposed Design_1 MPA). The overall volume of this MPA is reduced by $57 \%$ from the conventional one. Using the same principle for Design_2 MPA, the patch area reduction and the volume reduction achieved are $35 \%$ and $25 \%$, respectively compared to its conventional proximity-coupled fed MPA. Similarly, for Design_3 MPA, the patch area reduction and the volume reduction achieved are $38 \%$ and $33 \%$, respectively compared to its conventional aperture-coupled fed MPA. 


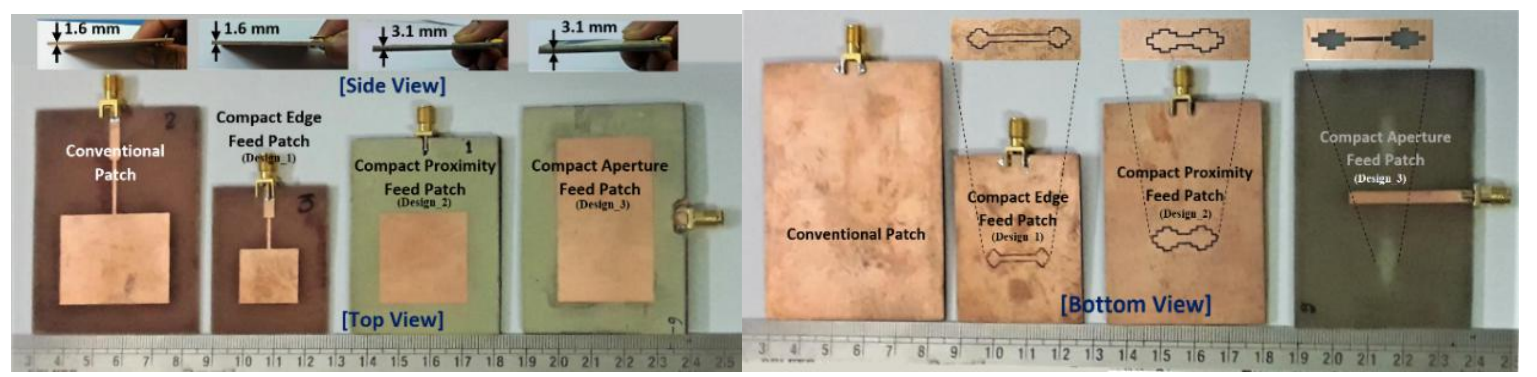

(a)

(b)

Fig. 7. Physically designed MPAs (Conventional microstrip line edge fed MPA and three compact MPAs) (a) Top View (b) Bottom view.

The vector surface current distribution on the ground plane of the conventional MPAs (microstrip line fed, proximity-coupled fed, and aperture-coupled fed) without DGS structure and the proposed MPAs with DGS structures are depicted in Fig. 8. From the figure, it is observed that the surface current covers a longer path on the ground plane of the MPA having DGS than the ground plane of the MPA having no DGS. Since the surface current covers a longer path, there is an increase in electrical path length, and subsequently, the frequency of resonance decreases. As the physical dimension of the MPA remains constant and the frequency of resonance decreases, size reduction is said to be achieved. It is also observed from the figure that in the proposed Design_1 MPA, the path covered by the surface current is highest, so the size reduction is also highest in Design_1 MPA.

The dimensions of the three MPAs along with the \% size reduction are mentioned in Table IV. It is observed that Design_1 MPA gives the best size reduction as compared to the other two MPAs. Although the dimensions of the Design_2 antenna and Design_3 antenna are more as compared to the Design_1 antenna, the performances of these two antennas are much better than the Design_1 antenna. The performance parameters of the three MPAs are discussed in the result and discussion section. Comparative studies of these MPAs with their conventional ones and with the designs available in the literature are also discussed in this section. 


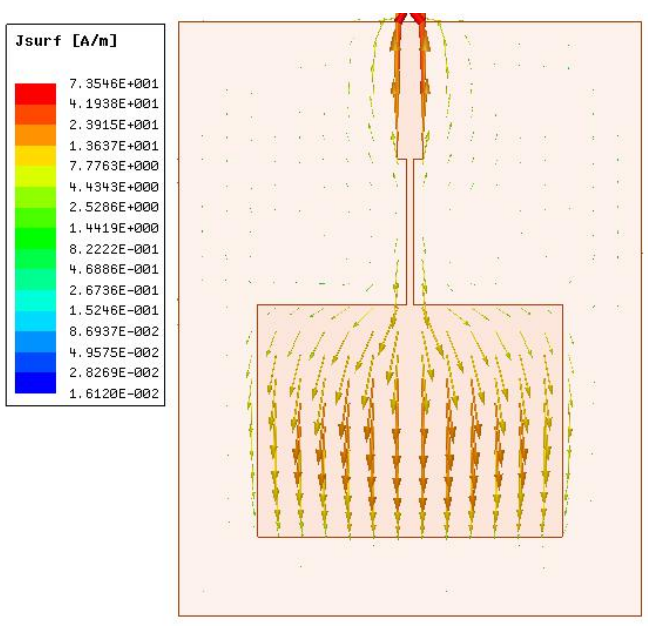

(a)

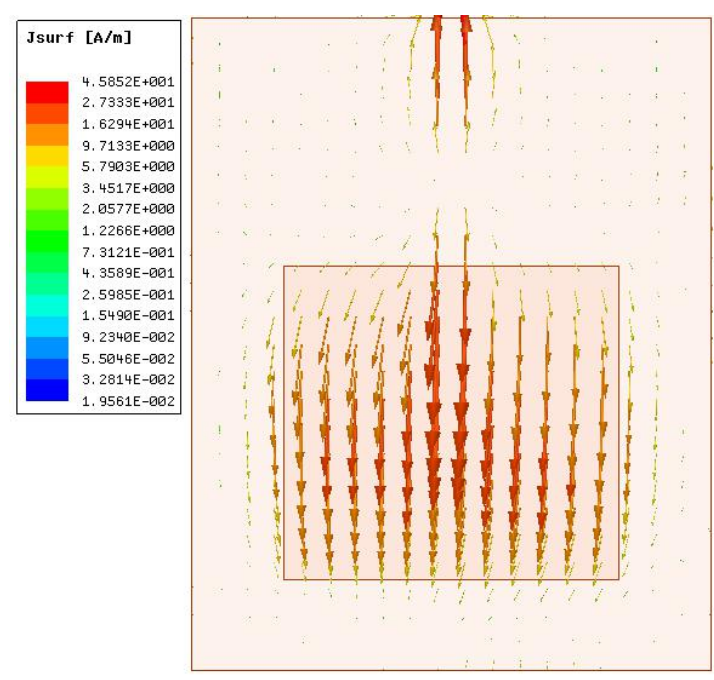

(c)

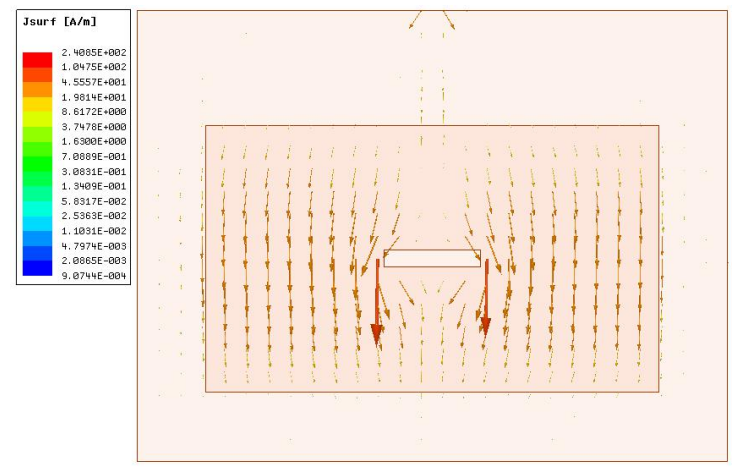

(e)

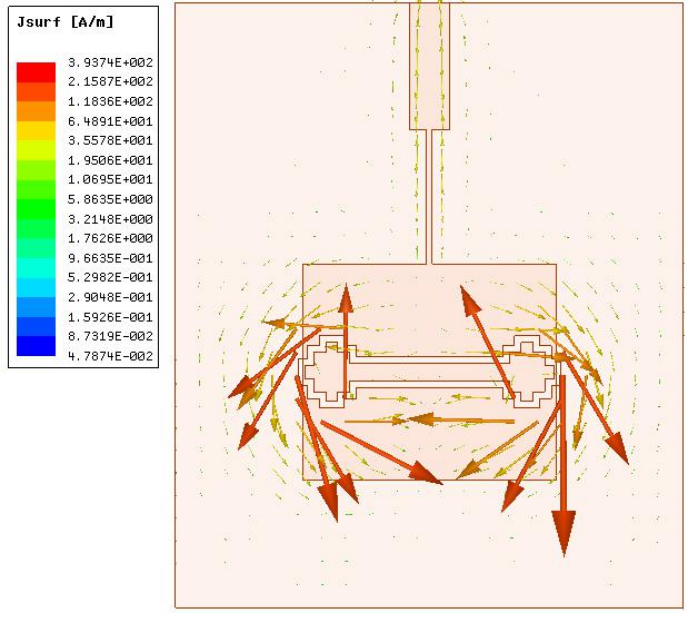

(b)

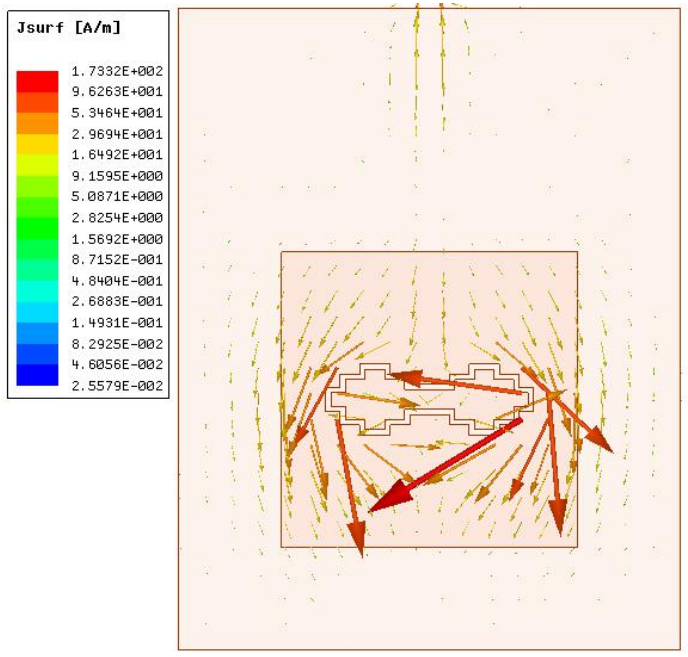

(d)

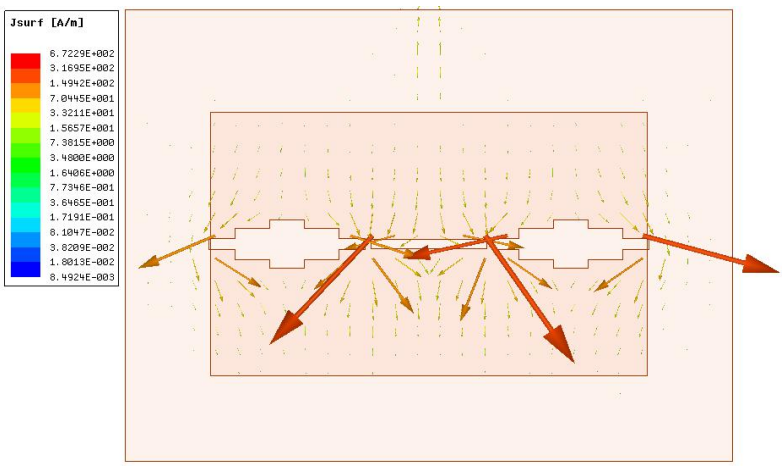

(f)

Fig. 8. The distribution of surface current on the ground plane of the conventional and proposed MPAs (a) Design_1 MPA (Conventional) (b) Design_1 MPA (Proposed) (c) Design_2 MPA (Conventional) (d) Design_2 MPA (Proposed) (e) Design_3 MPA (Conventional) (f) Design_3 MPA (Proposed). 

DOI: http://dx.doi.org/10.1590/2179-10742021v20i21165

TABle IV. Summarized Dimensions of CONVENTIONAL AND COMPACt MPAs AT 2.4 GHz FReQUency

\begin{tabular}{|c|c|c|c|c|c|c|c|}
\hline \multirow{2}{*}{\multicolumn{2}{|c|}{$\begin{array}{l}\text { Antenna } \\
\text { Dimensions }\end{array}$}} & \multicolumn{2}{|c|}{ Design_1 MPA } & \multicolumn{2}{|c|}{ Design_2 MPA } & \multicolumn{2}{|c|}{ Design_3 MPA } \\
\hline & & Conventional & Proposed & Conventional & Proposed & Conventional & Proposed \\
\hline \multirow{3}{*}{$\begin{array}{l}\text { Antenna } \\
\text { Volume }\end{array}$} & In $\mathrm{mm}^{3}$ & $56.1 \times 71.8 \times 1.6$ & $38.31 \times 45.61 \times 1.6$ & $54.4 \times 68.7 \times 3.1$ & $46.86 \times 60.07 \times 3.1$ & $81.94 \times 62.48 \times 3.1$ & $68.31 \times 50.59 \times 3.1$ \\
\hline & In $\lambda_{0}{ }^{3}$ & $0.44 \times 0.57 \times 0.013$ & $0.30 \times 0.36 \times 0.013$ & $0.43 \times 0.54 \times 0.025$ & $0.37 \times 0.48 \times 0.024$ & $0.65 \times 0.49 \times 0.025$ & $0.54 \times 0.40 \times 0.024$ \\
\hline & $\begin{array}{l}\text { Size } \\
\text { Reduced }\end{array}$ & --- & $57 \%$ & --- & $25 \%$ & --- & $33 \%$ \\
\hline \multirow{3}{*}{$\begin{array}{l}\text { Antenna } \\
\text { Surface } \\
\text { Area }\end{array}$} & In $\mathrm{mm}^{2}$ & $56.1 \times 71.8$ & $38.31 \times 45.61$ & $54.4 \times 68.7$ & $46.86 \times 60.07$ & $81.94 \times 62.48$ & $68.31 \times 50.59$ \\
\hline & In $\lambda_{0}^{2}$ & $0.44 \times 0.57$ & $0.30 \times 0.36$ & $0.43 \times 0.54$ & $0.37 \times 0.48$ & $0.65 \times 0.49$ & $0.54 \times 0.40$ \\
\hline & $\begin{array}{l}\text { Size } \\
\text { Reduced }\end{array}$ & --- & $57 \%$ & --- & $25 \%$ & --- & $33 \%$ \\
\hline \multirow{3}{*}{ Patch Area } & In $\mathrm{mm} 2$ & $36.8 \times 28.1$ & $19.11 \times 16.34$ & $35.2 \times 32.96$ & $27.66 \times 27.66$ & $62.74 \times 37$ & $49.11 \times 29.5$ \\
\hline & In $\lambda_{0}{ }^{2}$ & $0.29 \times 0.22$ & $0.15 \times 0.13$ & $0.28 \times 0.26$ & $0.22 \times 0.22$ & $0.51 \times 0.29$ & $0.39 \times 0.23$ \\
\hline & $\begin{array}{l}\text { Size } \\
\text { Reduced }\end{array}$ & --- & $70 \%$ & --- & $35 \%$ & --- & $38 \%$ \\
\hline
\end{tabular}

\section{RESUlt AND Discussion}

The complete process of the proposed antenna miniaturization involves the design of conventional MPAs, selection of proper fractal DGS, application of sensitivity analysis, and optimization using the pattern search algorithm to develop compact designs with improved performance characteristics. To make a valid comparison among the three proposed compact designs and the other compact designs from literature, the conventional microstrip line fed antenna is considered as the reference antenna. All antenna designs and optimization processes are performed in the ANSYS HFSS design environment. Using the optimized design parameters, the conventional MPA and three miniaturized MPAs are physically designed. The performance parameters of the fabricated MPAs are measured and validated with their simulated ones. Finally, the proposed MPA designs are compared with the conventional MPA and other MPAs available in the literature.

\section{A. S11 Characteristics}

The simulated S11 characteristics and measured S11 characteristics of conventional MPA and Design_1 MPA are shown in Fig. 9. Similarly, the simulated S11 characteristics and measured S11 characteristics of Design_2 MPA and Design_3 MPA are shown in Fig. 10. From both the figures it is observed that all the simulated designs are resonating at $2.4 \mathrm{GHz}$ while all the physically fabricated MPAs are resonating very close to $2.4 \mathrm{GHz}$. Among the physically designed antennas, the Design_2 antenna has the highest BW of $120 \mathrm{MHz}$ in comparison to the $50 \mathrm{MHz} \mathrm{BW}$ of the conventional microstrip line fed antenna. In all the cases, the $\mathrm{S} 11$ has a value below $-20 \mathrm{~dB}$ at 2.4 $\mathrm{GHz}$ indicating superior impedance matching. After the S11 parameter is measured, the radiation 
patterns of the MPAs are determined.

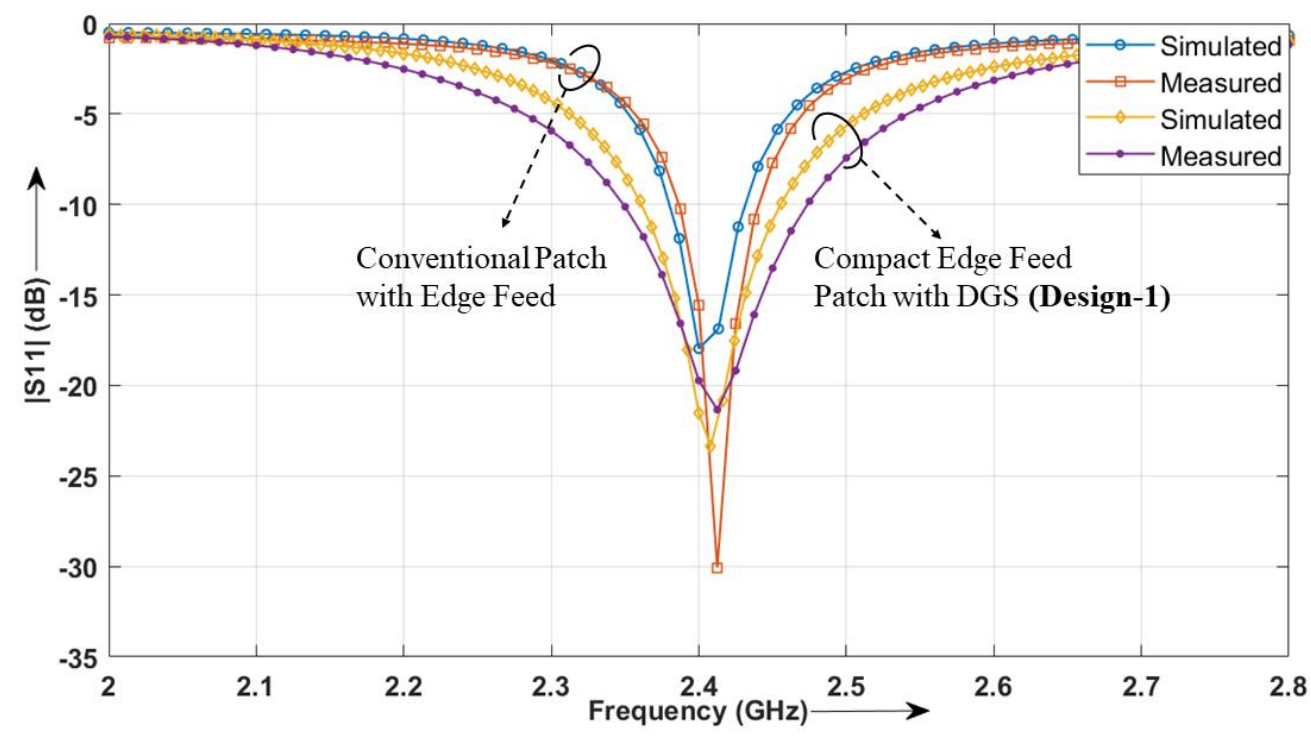

Fig. 9. S11 characteristics of simulated and fabricated MPAs (Conventional MPA with edge feed and compact Design_1 MPA with edge feed).

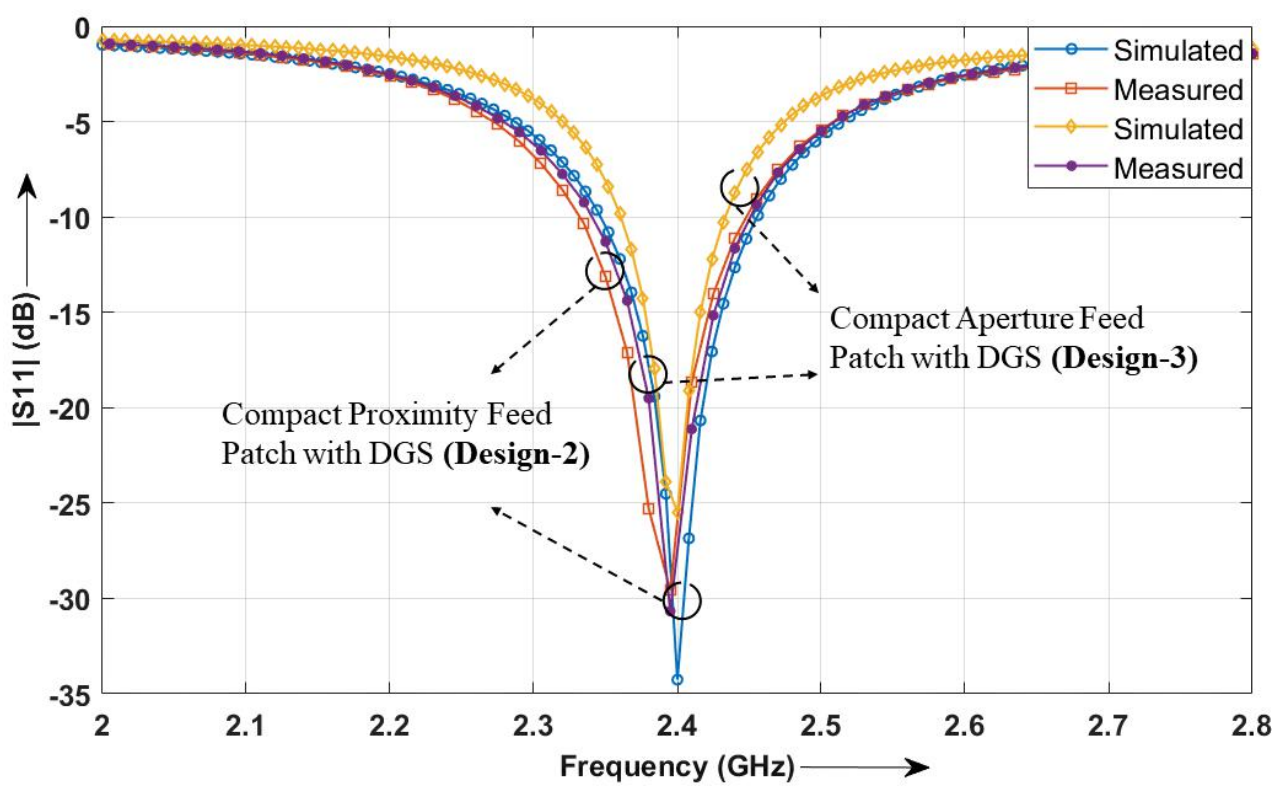

Fig. 10. S11 characteristics of simulated and fabricated MPAs (Compact Design_2 MPA with proximity-coupled feed and compact Design_3 MPA with aperture-coupled feed).

\section{B. Radiation Characteristics}

The arrangements for the measurement of radiation patterns of MPAs are as shown in Fig. 11. A horn antenna with a known gain of $8 \mathrm{dBi}$ at a frequency of $2.4 \mathrm{GHz}$ is used as a transmitting antenna. The four fabricated MPAs are placed individually as a receiving antenna for pattern measurement. The power received by the receiving antenna is measured with the help of a power sensor at different elevation and azimuthal angles. 

DOI: http://dx.doi.org/10.1590/2179-10742021v20i21165

The measured and simulated E-plane (XZ plane, $\left.\phi=0^{0}\right)$ pattern of conventional edge feed MPA and three compact MPAs are as shown in Fig. 12. Similarly, the simulated and measured H-plane (YZ plane, $\phi=90^{\circ}$ ) patterns of these four MPAs are as shown in Fig. 13.

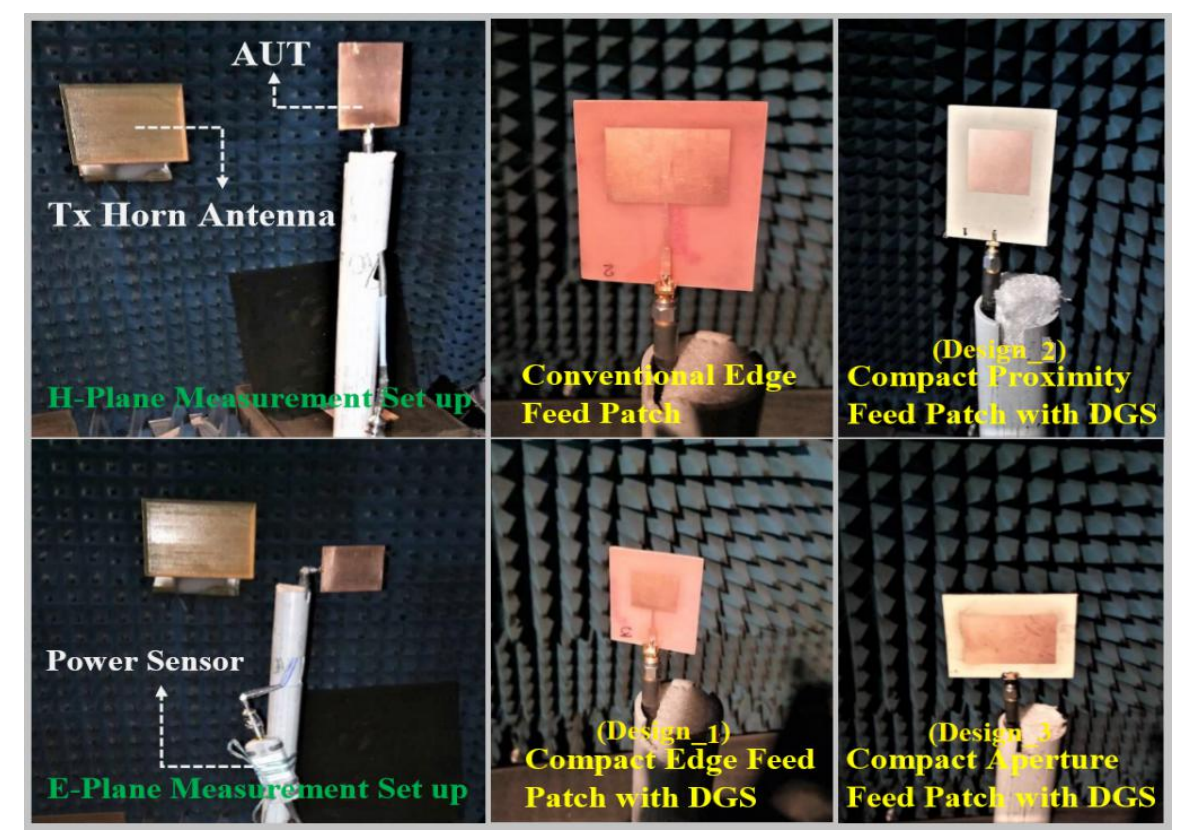

Fig. 11. The measurement of E-plane pattern and H-plane patterns of the four MPAs in an anechoic chamber.

The symmetric broadside E-plane pattern is observed for all the MPAs. Likewise, the H-plane pattern with small variation in symmetry is observed for the MPAs due to the DGS structures. However, there is a good degree of matching between the measured and simulated gain of the MPAs for both E-plane as well as H-plane. The minor deviations are due to small imperfections in the fabrication process. It is observed that the gain of Design_3 MPA is highest (maximum of $5.91 \mathrm{dBi}$ in E-plane as well as Hplane) among all the four fabricated MPAs. The maximum gain of Design_1 MPA is found to be 1.43 $\mathrm{dBi}$, which is the lowest one. Since the gain of an MPA is dependent on the patch area, the Design_1 MPA with the smallest patch area provides the lowest gain. Depending upon the requirement, the compromise is made between the size and gain of an MPA. 


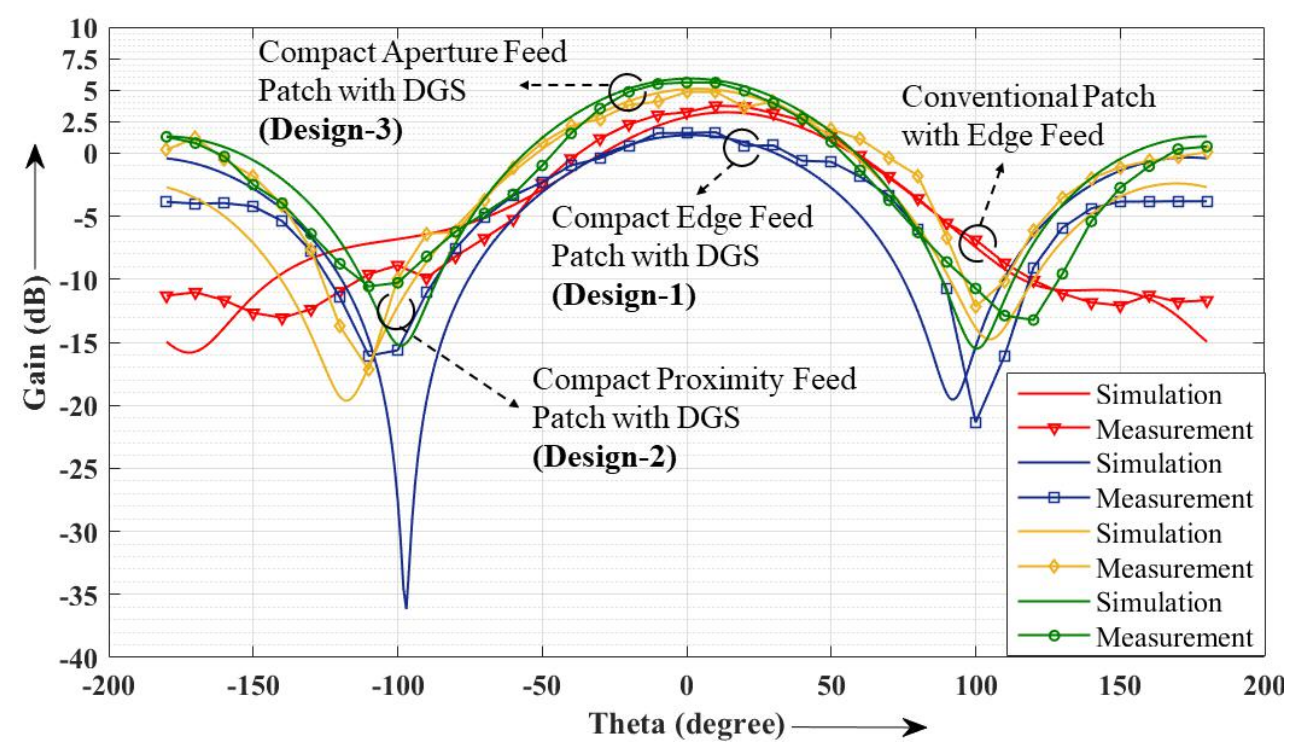

Fig. 12. The measured and simulated E-plane $\left(\mathrm{XZ}\right.$ plane, $\left.\phi=0^{\circ}\right)$ pattern of all four MPAs (Conventional MPA with edge feed, compact Design_1 MPA with edge feed, compact Design_2 MPA with proximity-coupled feed, and compact Design_3 MPA with aperture-coupled feed) at $2.4 \mathrm{GHz}$.

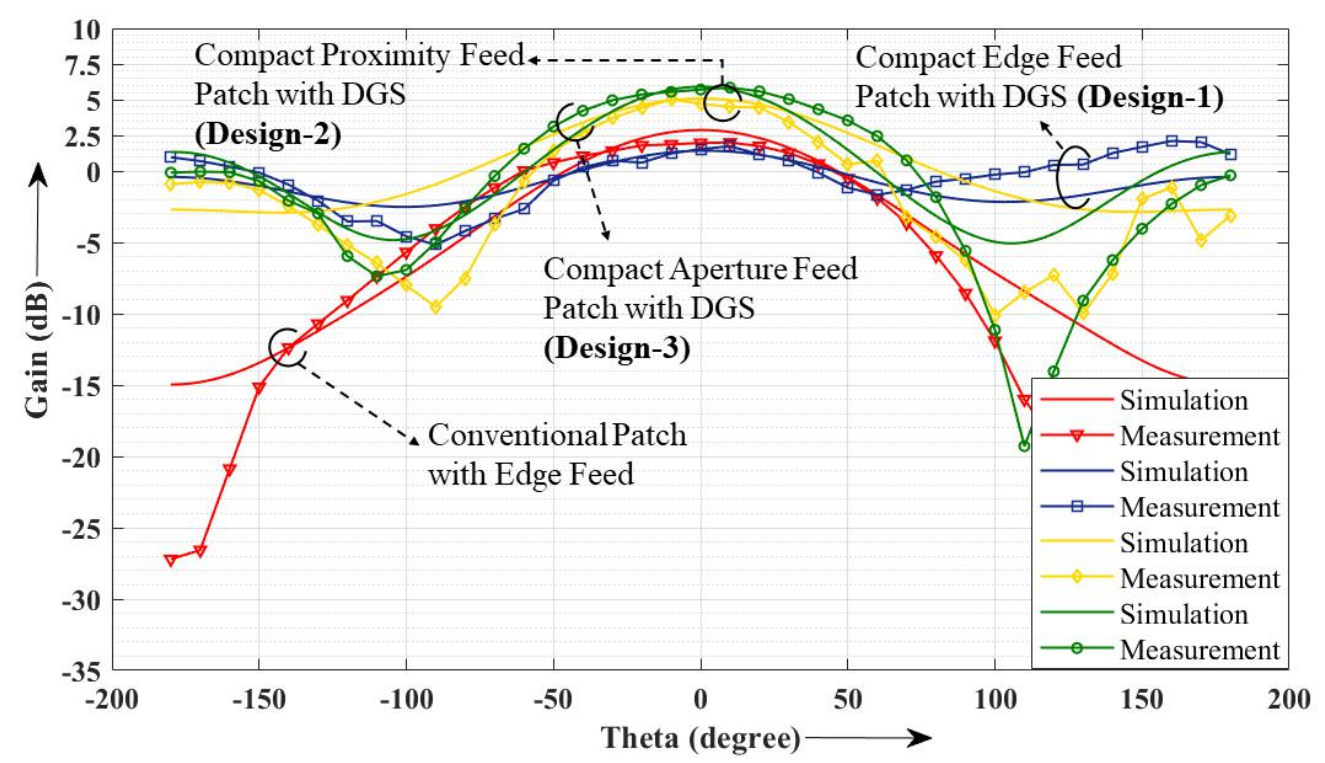

Fig. 13. The measured and simulated H-plane (YZ plane, $\left.\phi=90^{\circ}\right)$ pattern of all four MPAs (Conventional MPA with edge feed, compact Design_1 MPA with edge feed, compact Design_2 MPA with proximity-coupled feed, and compact Design_3 MPA with aperture-coupled feed) at $2.4 \mathrm{GHz}$.

Polar form representations of radiation patterns (E-plane/H-plane) for the four MPAs are depicted in Fig. 14. Each of these figures shows both co-polarization (CP) as well as cross-polarization (XP) patterns of simulated and fabricated MPAs. The CP pattern of the E-plane is similar to a monopole for Desigm_1 MPA. The H-plane pattern is almost omnidirectional for this compact MPA. Due to the fractal DGS, there is minor degradation in the CP radiation pattern of the three MPAs in comparison to the conventional MPA. This is clearly understood from Fig. 14. It is noticed from Fig. 14 that for all the MPAs, the simulated and measured CP patterns are closely matching for E-plane. Also, the simulated and measured XP patterns are matching with each other for the E-plane of an MPA. Further, 
CP and XP patterns are sufficiently apart from each other. Similarly, for all the MPAs, the simulated and measured patterns are closely matching for H-plane and the $\mathrm{CP}$ and XP patterns are sufficiently apart from each other for the H-plane of an MPA.

For all the compact MPAs, the isolation between $\mathrm{CP}$ and XP level is around $30 \mathrm{~dB}$ in the H-plane radiation patterns which undoubtedly shows the polarization purity. It is observed that the compact MPAs have a lower gain as compared to their conventional MPAs. It is because of the massive size reduction achieved in the compact MPAs. Also, the DGS causes back radiation which further reduces the gain of an antenna. Therefore, for achieving miniaturization, sacrifice has to be done for gain.

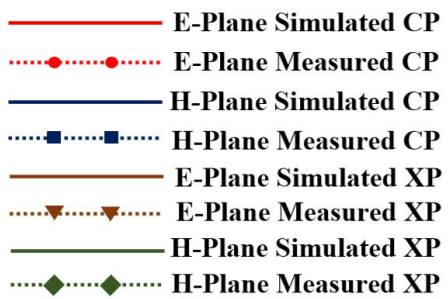

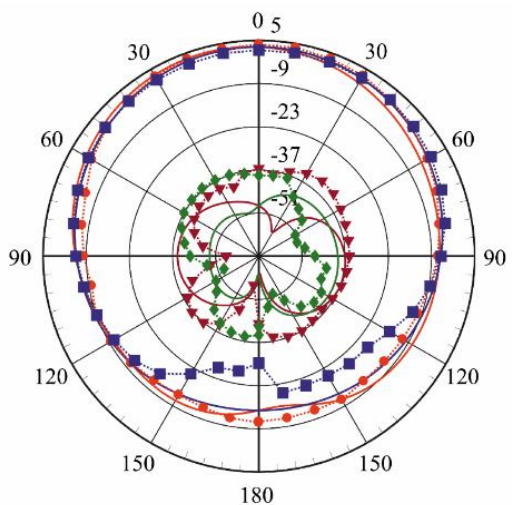

(a) Conventional MPA

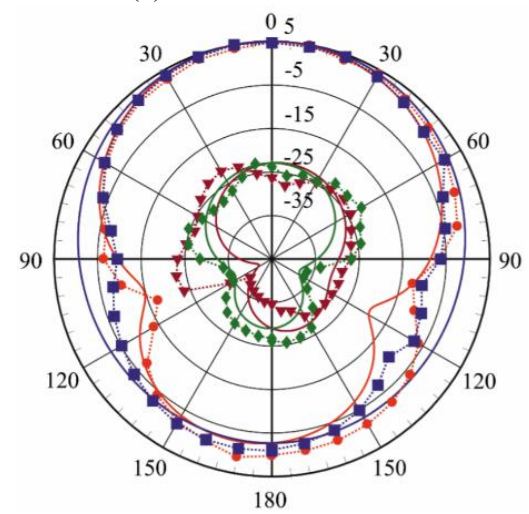

(c) Design_2 MPA

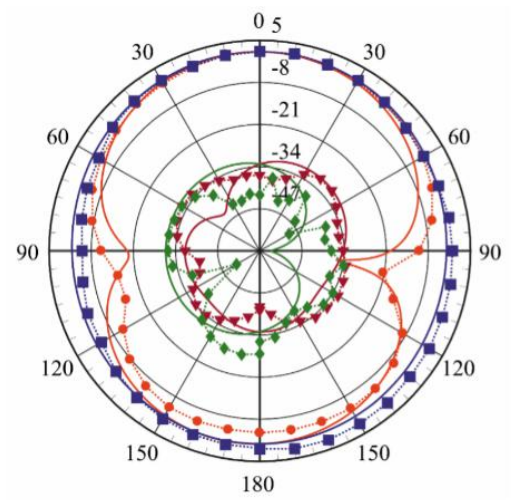

(b) Design_1 MPA

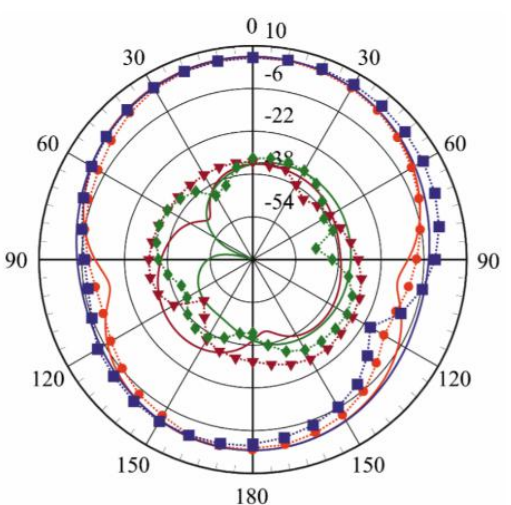

(d) Design_3 MPA

Fig. 14. Measured and simulated CP and XP radiation patterns for all the four fabricated MPAs at $2.4 \mathrm{GHz}$.

\section{Comparison of Compact MPAs with Their Conventional MPAs and Other Compact MPAs Available in the Literature}

The measured and simulated results of the conventional MPAs and their corresponding proposed compact MPAs are mentioned in Table V. It shows that the proposed compact designs have improved 
input impedance characteristics ( $\mathrm{Z}_{11}$ has real part close to $50 \mathrm{Ohm}$ and imaginary part close to $\left.0 \mathrm{Ohm}\right)$ as compared to their conventional designs. The peak realized gain, peak directivity, and radiation efficiency of the MPAs are also mentioned in the table. The proposed Design_3 MPA has the highest radiation efficiency of $91.3 \%$ among all the MPAs. It may be noted from the table that the performance parameters of the MPAs such as bandwidth, impedance matching, and radiation efficiency are improved using the proposed technique along with the size reduction. But there is a small decrement in peak gain of the proposed MPAs as compared to their conventional designs.

TABle V. Summarized PERFormances OF THE MPAS

\begin{tabular}{|c|c|c|c|c|c|c|c|}
\hline \multirow{2}{*}{\multicolumn{2}{|c|}{ Performance Parameters }} & \multicolumn{2}{|c|}{ Design_1 MPA } & \multicolumn{2}{|c|}{ Design_2 MPA } & \multicolumn{2}{|c|}{ Design_3 MPA } \\
\hline & & Conventional & $\begin{array}{l}\text { Proposed } \\
\text { MPA }\end{array}$ & Conventional & $\begin{array}{l}\text { Proposed } \\
\text { MPA }\end{array}$ & Conventional & $\begin{array}{l}\text { Proposed } \\
\text { MPA }\end{array}$ \\
\hline \multicolumn{2}{|c|}{ Resonant Frequency (GHz) } & 2.40 & 2.40 & 2.40 & 2.40 & 2.40 & 2.40 \\
\hline \multicolumn{2}{|c|}{$\mathrm{S} 11(\mathrm{~dB})$} & -17 & -23 & -34.49 & -34 & -35.73 & -25 \\
\hline \multicolumn{2}{|c|}{ Bandwidth (MHz) } & 50 & 100 & 80 & 110 & 60 & 70 \\
\hline \multicolumn{2}{|c|}{$\begin{array}{l}\text { Measured Resonant Frequency } \\
\qquad(\mathrm{GHz})\end{array}$} & 2.413 & 2.41 & --- & 2.395 & --- & 2.395 \\
\hline \multicolumn{2}{|c|}{ Measured Bandwidth (MHz) } & 50 & 115 & --- & 120 & --- & 105 \\
\hline \multirow{2}{*}{$\begin{array}{l}\text { Simulated CP } \\
\text { Gain }(\mathrm{dBi})\end{array}$} & E-Plane & 3.22 & 1.43 & 5.97 & 5.11 & 7.64 & 5.91 \\
\hline & H- Plane & 2.87 & 1.42 & 5.91 & 5.08 & 7.64 & 5.91 \\
\hline \multirow{2}{*}{$\begin{array}{l}\text { Measured CP } \\
\text { Gain }(\mathrm{dBi})\end{array}$} & E- Plane & 3.76 & 1.60 & --- & 4.85 & --- & 5.60 \\
\hline & H- Plane & 1.86 & 1.53 & --- & 4.72 & --- & 5.54 \\
\hline \multirow{2}{*}{$\begin{array}{l}\text { Simulated XP } \\
\text { Gain }(\mathrm{dBi})\end{array}$} & E-Plane & -36 & -30 & -18 & -23 & -29 & -31 \\
\hline & H-Plane & -38 & -30 & -18 & -23 & -34 & -32 \\
\hline \multirow{4}{*}{$\begin{array}{l}\text { Measured XP } \\
\text { Gain (dBi) } \\
\text { Z11 (Ohm) }\end{array}$} & E-Plane & -36 & -36 & -- & -23 & -- & -32 \\
\hline & H-Plane & -38 & -42 & --- & -26 & --- & -33 \\
\hline & Real & 41 & 48.93 & 48 & 48.40 & 49 & 55.57 \\
\hline & Imag. & 3 & 6.64 & -0.8 & 1.04 & -1 & -0.73 \\
\hline \multicolumn{2}{|c|}{ Peak Realized Gain (dBi) } & 3.1 & 1.4 & 5.9 & 5.1 & 7.6 & 5.9 \\
\hline \multicolumn{2}{|c|}{ Peak Directivity (dBi) } & 6.7 & 3.3 & 6.8 & 5.9 & 8 & 6.3 \\
\hline \multicolumn{2}{|c|}{ Radiation Efficiency } & $44 \%$ & $65 \%$ & $82 \%$ & $84 \%$ & $91 \%$ & $91.3 \%$ \\
\hline
\end{tabular}

To authenticate our proposed miniaturization technique, a comparative study is done among the proposed compact MPAs, conventional edge feed MPA, and the other miniaturized MPAs available in the literature. This is mentioned in Table VI. Along with the data from journal papers, the table contains the data from two leading antenna manufacturing companies, one is D-link [21] and the other one is Taoglas [22]. The conventional microstrip line edge fed MPA is selected as the reference antenna and the $\%$ of patch area reduction and antenna surface area reduction is calculated with respect to this reference antenna. The ' + ' sign in \% of reduction indicates that the compared antenna has less area as compared to the reference antenna. The '-' sign indicates that the compared antenna has more area as compared to the reference antenna. The MPAs are compared in terms of three important aspects of an antenna that are antenna dimension, $-10 \mathrm{~dB}$ S11 bandwidth, and antenna gain. From Table VI it is observed that the compact Design_1 MPA achieves a reduction in patch area of $69.8 \%$ and reduction in overall surface area of the antenna of $56.62 \%$ with respect to the reference MPA. 
Table VI. Performance Comparison of Proposed MPAs with Some of The Compact MPAs Available IN the LITERATURE

\begin{tabular}{|c|c|c|c|c|c|c|}
\hline $\begin{array}{c}\text { MPAs } \\
\text { for Comparison }\end{array}$ & $\begin{array}{l}\text { Resonant } \\
\text { frequency } \\
(\mathbf{G H z})\end{array}$ & $\begin{array}{c}\text { Antenna } \\
\text { Surface Area }\left(\mathbf{m m}^{2}\right) \\
/ \\
\text { Patch Area }\left(\mathbf{m m}^{2}\right)\end{array}$ & $\begin{array}{c}\text { Surface area } \\
\text { reduction / } \\
\text { Patch area } \\
\text { reduction }\end{array}$ & $\begin{array}{c}\text { BW } \\
\text { (MHz) }\end{array}$ & $\begin{array}{c}\text { Simulated/Measured } \\
\text { Gain } \\
(\mathbf{d B i})\end{array}$ & $\begin{array}{l}\text { Miniaturization } \\
\text { method }\end{array}$ \\
\hline $\begin{array}{l}\text { Conventional } \\
\text { microstrip line fed } \\
\text { MPA }\end{array}$ & 2.40 & $\begin{array}{l}56.1 \times 71.8 \\
36.8 \times 28.1\end{array}$ & Taken as reference & 50 & 3.24 & ------ \\
\hline$[6]$ & 2.40 & $\begin{array}{c}34 \times 34 \\
12.4 \times 19.2\end{array}$ & $\begin{array}{l}+71.3 \% \\
+76.97 \%\end{array}$ & 25 & -2.02 & $\begin{array}{l}\text { Using split ring } \\
\text { resonators }\end{array}$ \\
\hline $\begin{array}{c}{[21]} \\
\text { Datasheet (D-Link: } \\
\text { DWL-R60AT) }\end{array}$ & 2.40 & $\begin{array}{l}58.4 \times 58.4 \\
\text { NA }\end{array}$ & $\begin{array}{l}+15.32 \% \\
\text { NA }\end{array}$ & 83.5 & 6.0 & NA \\
\hline $\begin{array}{c}{[22]} \\
\text { Datasheet (Taoglas: } \\
\text { WCM.01.0151W) }\end{array}$ & 2.45 & $\begin{array}{c}100 \times 100 \\
19.8 \times 14.3\end{array}$ & $\begin{array}{c}-148.26 \% \\
+72.61\end{array}$ & 200 & 2.02 & NA \\
\hline [23] & 2.4 & $\begin{array}{l}78 \times 78 \\
\text { NA }\end{array}$ & $\begin{array}{l}-51.04 \% \\
\text { NA }\end{array}$ & 140 & 0.46 & $\begin{array}{l}\text { Using modified } \\
\text { monopole }\end{array}$ \\
\hline$[24]$ & 2.4 & $\begin{array}{c}47.5 \times 20 \\
27 \times 11\end{array}$ & $\begin{array}{l}+76.41 \% \\
+71.27 \%\end{array}$ & 110 & 2.39 & Using shorting pin \\
\hline$[25]$ & 2.4 & $\begin{array}{l}72 \times 72 \\
30 \times 30\end{array}$ & $\begin{array}{l}-28.69 \% \\
+12.96 \%\end{array}$ & 410 & 6 & $\begin{array}{l}\text { Using meander-line and } \\
\text { trident arms with } \\
\text { arrowhead-shaped tips }\end{array}$ \\
\hline$[26]$ & 2.4 & $\begin{array}{c}33 \times 41 \\
\text { NA }\end{array}$ & $\begin{array}{c}+66.40 \% \\
\text { NA }\end{array}$ & 240 & 4.2 & $\begin{array}{l}\text { Using monopole and } \\
\text { inverted-F antenna } \\
\text { Using loop-type }\end{array}$ \\
\hline [27] & 2.4 & $\begin{array}{c}120 \times 60 \\
12 \times 6\end{array}$ & $\begin{array}{c}-78.74 \\
+93.03 \%\end{array}$ & 210 & 2.62 & $\begin{array}{l}\text { inductive couplers and } \\
\text { series-resonant feeding } \\
\text { circuits }\end{array}$ \\
\hline$[28]$ & 2.45 & $\begin{array}{c}46.4 \times 46.4 \\
\pi \times 17.4^{2}\end{array}$ & $\begin{array}{l}+46.54 \% \\
+8.01 \%\end{array}$ & NA & 6 & $\begin{array}{l}\text { Using circular shaped } \\
\text { DGS }\end{array}$ \\
\hline [29] & 2.45 & $\begin{array}{c}60 \times 40 \\
34 \times 8\end{array}$ & $\begin{array}{l}+40.41 \% \\
+73.69 \%\end{array}$ & NA & 1.48 & $\begin{array}{l}\text { Using a fork-type } \\
\text { ground plane and non- } \\
\text { uniform } \\
\text { meander-line }\end{array}$ \\
\hline$[30]$ & 2.44 & $\begin{array}{c}64 \times 62 \\
\text { NA }\end{array}$ & $\begin{array}{c}+1.48 \% \\
\text { NA }\end{array}$ & 110 & 1.65 & Using shorting vias \\
\hline$[31]$ & 2.44 & $\begin{array}{c}60 \times 60 \\
\text { NA }\end{array}$ & $\begin{array}{c}+10.62 \% \\
\text { NA }\end{array}$ & 80 & 2.85 & $\begin{array}{l}\text { Using complementary } \\
\text { split ring resonators and } \\
\text { metamaterial }\end{array}$ \\
\hline [32] & 2.42 & $\begin{array}{c}30 \times 52.6 \\
\text { NA }\end{array}$ & $\begin{array}{c}+60.82 \% \\
\text { NA }\end{array}$ & 310 & 0.28 & $\begin{array}{l}\text { Using complementary } \\
\text { split ring resonators and } \\
\text { metamaterial }\end{array}$ \\
\hline [33] & 2.45 & $\begin{array}{c}60 \times 77 \\
\text { NA }\end{array}$ & $\begin{array}{l}-14.69 \% \\
\text { NA }\end{array}$ & 343 & -1.3 & $\begin{array}{l}\text { Using the parallel } \\
\text { coupled microstrip line } \\
\text { and the inverted-L } \\
\text { antenna }\end{array}$ \\
\hline$[34]$ & 2.4 & $\begin{array}{c}50 \times 55 \\
\text { NA }\end{array}$ & $\begin{array}{l}+31.72 \% \\
\text { NA }\end{array}$ & 401 & 2.4 & $\begin{array}{l}\text { Using monopole } \\
\text { antenna with modified } \\
\text { split ring resonators }\end{array}$ \\
\hline$[35]$ & 2.4 & $\begin{array}{c}55 \times 55 \\
\text { NA }\end{array}$ & $\begin{array}{c}+24.90 \% \\
\text { NA }\end{array}$ & 100 & 3.5 & $\begin{array}{l}\text { Using coupled } \\
\text { stripline open-loop } \\
\text { resonators }\end{array}$ \\
\hline$[36]$ & 2.45 & $\begin{array}{l}40 \times 40 \\
\text { NA }\end{array}$ & $\begin{array}{l}+60.27 \% \\
\text { NA }\end{array}$ & 600 & 2.1 & $\begin{array}{l}\text { Using split ring } \\
\text { resonators and } \\
\text { metamaterial }\end{array}$ \\
\hline [37] & 2.45 & $\begin{array}{c}50 \times 50 \\
\text { NA }\end{array}$ & $\begin{array}{l}+37.93 \% \\
\text { NA }\end{array}$ & 343 & 1.03 & $\begin{array}{l}\text { Using a coupled line } \\
\text { resonator and a } \Gamma- \\
\text { shaped antenna }\end{array}$ \\
\hline [38] & 2.45 & $\begin{array}{l}\text { NA } \\
\text { NA }\end{array}$ & $\begin{array}{l}\text { NA } \\
\text { NA }\end{array}$ & 85.01 & 1.27 & $\begin{array}{l}\text { Using tetra-circle } \\
\text { fractal patch elements }\end{array}$ \\
\hline $\begin{array}{c}\text { Compact Design_1 } \\
\text { MPA }\end{array}$ & 2.40 & $\begin{array}{l}38.31 \times 45.61 \\
19.11 \times 16.34\end{array}$ & $\begin{array}{l}+56.62 \% \\
+69.80 \%\end{array}$ & 100 & 1.43 & $\begin{array}{c}\text { Using Type2 Iter1 Wire } \\
\text { Fractal DGS }\end{array}$ \\
\hline $\begin{array}{c}\text { Compact Design_2 } \\
\text { MPA }\end{array}$ & 2.40 & $\begin{array}{l}46.86 \times 60.07 \\
27.66 \times 27.66\end{array}$ & $\begin{array}{l}+30.11 \% \\
+26.01 \%\end{array}$ & 110 & 5.11 & $\begin{array}{c}\text { Using Type2 Iter1 Wire } \\
\text { Fractal DGS }\end{array}$ \\
\hline $\begin{array}{c}\text { Compact Design_3 } \\
\text { MPA }\end{array}$ & 2.40 & $\begin{array}{l}68.31 \times 50.5 \\
49.11 \times 29.5\end{array}$ & $\begin{array}{l}+14.35 \% \\
-40.09 \%\end{array}$ & 70 & 5.91 & $\begin{array}{l}\text { Using Type } 2 \text { Iter1 } \\
\text { Fractal DGS }\end{array}$ \\
\hline
\end{tabular}


The compact antenna reported in [6] has a patch area reduction of $76.97 \%$ which is the secondhighest among all the reference MPAs and it is achieved using complementary split-ring resonators. On the other hand, the MPA has a low gain and BW of -2.02 dBi and $25 \mathrm{MHz}$, respectively. In [2122], the datasheets of two practical antennas DWL-R60AT from D-link and WCM.01.0151W from Taoglas are mentioned to give an idea about the dimension of MPAs in the current scenario. The MPA mentioned in [23] has a surface area reduction of $-51.04 \%$ which indicates the antenna has $51.04 \%$ more surface area as compared to the reference antenna. In [27] the MPA has the highest patch area reduction of $93.03 \%$ but on the other hand, it has a large surface area of $120 \times 60 \mathrm{~mm}^{2}$. The proposed Design_2 MPA has a reduction in patch area of 35\% and a reduction in overall surface area of $25 \%$ with respect to the corresponding conventional proximity-coupled fed MPA as mentioned in Table IV. But it has a patch area reduction of $26.01 \%$ and surface area reduction of $30.11 \%$ with respect to conventional microstrip line fed MPA. However, the proposed Design_2 MPA has a higher gain of $5.11 \mathrm{dBi}$ compared to many of the structures reported in Table VI. Similarly, the proposed Design_3 MPA has a reduction in patch area of 38\% and a reduction in overall surface area of 33\% with respect to the corresponding conventional aperture-coupled fed MPA as mentioned in Table IV. But it has a patch area reduction of $-40.09 \%$ and surface area reduction of $14.35 \%$ with respect to conventional microstrip line fed MPA. However, the proposed Design_3 MPA has the second-highest gain of $5.91 \mathrm{dBi}$ compared to $6 \mathrm{dBi}$ as mentioned in Table VI. Whenever space is a constraint and a highly miniaturized MPA is needed, the Design_1 MPA can be used. The Design_2 can be used where moderate miniaturization and higher gain are required. The Design_3 MPA can be used in a situation where space is not a constraint but high gain is required. Thus, it is observed that the proposed MPAs may not be best in all performance parameters but they have balanced performance characteristics along with the small size as compared to other MPAs available in the literature.

The introduction of 'Fractal-DGS' also ensues in generating a reactive loading which reduces the overall quality factor of an MPA. Although the quality factor is decreased, a number of performance parameters of the MPA such as bandwidth, impedance matching, radiation efficiency, etc. are improved. The proposed method of size reduction can be used for designing compact MPAs operating at any desired frequencies. The compact array antennas can be designed applying this technique. The M-MFDGS provides a size reduction of MPAs that are used for reflected antenna array with phase tuning characteristics remaining intact. Thus, for the high range wireless applications where space is a constraint, these compact MPAs can be used.

\section{CONCLUSION}

In this article, three compact MPAs are proposed. The M-MFDGS is used for antenna miniaturization and performance enhancement. The proposed MPAs are physically fabricated and performances are measured. For all the fabricated MPAs, the measured results well agree with the simulated results. Among the three MPAs, the Design_1 MPA achieves the highest 
miniaturization. Similarly, along with miniaturization, Design_2 MPA has a modest bandwidth and gain. Design_3 MPA has a very high gain along with miniaturization. Thus, M-MFDGS has a greater influence on patch antenna miniaturization and performance improvement of an MPA. These miniaturized MPAs can be suitably used for portable devices operating in the $2.4 \mathrm{GHz}$ frequency band. Further, this Modified Minkowski Fractal DGS concept can be extended for antenna array used for large scanning.

\section{REFERENCES}

[1] A. Boukarkar, X. -Q. Lin, Y. Jiang, and Y. -Q. Yu, "Miniaturized Single-Feed Multiband Patch Antennas," IEEE Trans. Antennas Propag., vol. 65, no. 2, pp. 850-854, 2017. doi: 10.1109/TAP.2016.2632620.

[2] A. Motevasselian, and W. G. Whittow, "Patch size reduction of rectangular microstrip antennas by means of a cuboid ridge," IET Microw. Antenna. Propag., vol. 9, no. 15, pp. 1727-1732, 2015. doi: 10.1049/iet-map.2014.0559.

[3] V. V. Reddy, and N. V. S. N. Sarma, "Compact Circularly Polarized Asymmetrical Fractal Boundary Microstrip Antenna for Wireless Applications," IEEE Antennas Wirel. Propag. Lett., vol. 13, pp. 118-121, 2014. doi: 10.1109/LAWP.2013.2296951.

[4] J. Oh, and K. Sarabandi, "A Topology-Based Miniaturization of Circularly Polarized Patch Antennas," IEEE Trans. Antennas Propag., vol. 61, no. 3, pp. 1422-1426, 2013. doi: 10.1109/TAP.2012.2231915.

[5] H. -X. Xu, G. -M. Wang, J. -G. Liang, M. Q. Qi, and X. Gao, "Compact Circularly Polarized Antennas Combining Meta-Surfaces and Strong Space-Filling Meta-Resonators," IEEE Trans. Antennas Propag., vol. 61, no. 7, pp. 34423450, 2013. doi: 10.1109/TAP.2013.2255855.

[6] Y. Dong, H. Toyao, and T. Itoh, "Design and Characterization of Miniaturized Patch Antennas Loaded with Complementary Split-Ring Resonators," IEEE Trans. Antennas Propag., vol. 60, no. 2, pp. 772-785, 2012. doi: 10.1109/TAP.2011.2173120.

[7] C. -S. Kim, J. -S. Park, D. Ahn, and J. -B. Lim, "A novel 1-D periodic defected ground structure for planar circuits," IEEE Microwave and Guided Wave Letters, vol. 10, no. 4, pp. 131-133, 2000. doi: 10.1109/75.846922.

[8] M. Yang, Z. N. Chen, P. Y. Lau, X. Qing, and X. Yin, "Miniaturized Patch Antenna with Grounded Strips," IEEE Trans. Antennas Propag., vol. 63, no. 2, pp. 843-848, 2015. doi: 10.1109/TAP.2014.2382668.

[9] J. Pei, A. -G. Wang, S. Gao, and W. Leng, "Miniaturized Triple-Band Antenna with a Defected Ground Plane for WLAN/WiMAX Applications," IEEE Antennas Wirel. Propag. Lett., vol. 10, pp. 298-301, 2011. doi: 10.1109/LAWP.2011.2140090.

[10] S. Xu, K. Ma, F. Meng, and K. S. Yeo, "Novel Defected Ground Structure and Two-Side Loading Scheme for Miniaturized Dual-Band SIW Bandpass Filter Designs," IEEE Microw. Wirel. Compon. Lett., vol. 25, no. 4, pp. 217219, 2015. doi: 10.1109/LMWC.2015.2400916.

[11] C. Kumar, and D. Guha, "Asymmetric Geometry of Defected Ground Structure for Rectangular Microstrip: A New Approach to Reduce its Cross-Polarized Fields," IEEE Trans. Antennas Propag., vol. 64, no. 6, pp. 2503-2506, 2016. doi: 10.1109/TAP.2016.2537360.

[12] M. Fallah, A. H. Nazeri, and M. R. Azadkhah, "A Novel Fractal Multi-band Frequency Selective Surface," J. Microw. Optoelectron. Electromagn. Appl., vol. 18, no. 2, pp. 276-285, 2019. doi: 10.1590/2179-10742019v18i21559.

[13] C. A. Balanis, Antenna Theory: Analysis and Design, $3^{\text {rd }}$ Ed., John Wiley \& Sons, 2005.

[14] G. P. Mishra, and B. B. Mangaraj, "Miniaturized microstrip patch design based on highly capacitive defected ground structure with fractal boundary for X-band microwave communications," IET Microw. Antenna. Propag., vol. 13, no. 10, pp. 1593-1601, 2019. doi: 10.1049/iet-map.2018.5778.

[15] K. Wei, J. Y. Li, L. Wang, R. Xu, and Z. J. Xing, "A New Technique to Design Circularly Polarized Microstrip Antenna by Fractal Defected Ground Structure," IEEE Trans. Antennas Propag., vol. 65, no. 7, pp. 3721-3725, 2017. doi: 10.1109/TAP.2017.2700226.

[16] R. Garg, P. Bhartia, I. Bahl, and A. Ittipiboon, Microstrip Antenna Design Hand Book, Artech House, 2001.

[17] C. C. Wong, and C. E. Free, "DGS pattern with enhanced effective capacitance," Electron. Lett., vol. 42, no. 8, pp. 470471, 2006. doi: 10.1049/el:20060316.

[18] ANSYS $^{\circledR}$ Electronics-High Frequency Electromagnetics, Release 19.1 Capabilities Brochure, Sensitivity Analysis Guide, ANSYS, Inc, 2018.

[19] B. B. Mangaraj, M. R. Jena, and S. K. Mohanty, "Bacteria Foraging Algorithm in Antenna Design," Appl. Comput. Intell. Soft Comput., vol. 2016, no. 1, pp. 1-11, 2016. doi:10.1155/2016/5983469.

[20] S. K. Mohanty, P. Swain, and B. B. Mangaraj, "Fuzzy logic biased optimal dipole-linear antenna array: An improved array with better trade-off between performance parameters," Prog. Electromagn. Res. B, vol. 79, pp. 167-190, 2017. doi:10.2528/PIERB17070402.

[21] Indoor 2.4 GHz Microstrip Antenna, D-Link DWL-R60AT Data Sheet, D-Link ${ }^{\circledR}$.

[22] $2.4 \mathrm{GHz}$ Wi-Fi/Bluetooth Microstrip Button Antenna, WCM.01.0151W Data Sheet, Taoglas ${ }_{\circledast}$.

[23] Y. Liu, J. Xue, H. Wang, and S. Gong, "Low-profile omnidirectional dual-polarised antenna for 2.4 GHz WLAN applications," Electron. Lett., vol. 50, no. 14, pp. 975-976, 2014. doi: 10.1049/el.2014.1146.

[24] Y. J. Cho, Y. S. Shin, and S. O. Park, "Internal PIFA for 2.4/5 GHz WLAN applications," Electron. Lett., vol. 42, no. 1, pp. 8-13, 2006. doi: 10.1049/el:20062998. 
[25] S. X. Ta, I. Park, and R. W. Ziolkowski, "Circularly Polarized Crossed Dipole on an HIS for 2.4/5.2/5.8-GHz WLAN Applications," IEEE Antennas Wirel. Propag. Lett., vol. 12, pp. 1464-1467, 2013. doi:10.1109/LAWP.2013.2288787.

[26] M. -A. Chung, and C. -F. Yang, "Built-in antenna design for $2.4 \mathrm{GHz}$ ISM band and GPS operations in a wrist-worn wireless communication device," IET Microw. Antenna. Propag., vol. 10, no. 12, pp. 1285-1291, 2016. doi: 10.1049/iet-map.2015.0785.

[27] R. Zhang, H. -H. Kim, and H. Kim, "Triple-band ground radiation antenna for GPS, WiFi 2.4 and 5 GHz band applications," Electron. Lett., vol. 51, no. 25, pp. 2082-2084, 2015. doi: 10.1049/el.2015.3440.

[28] M. K. Khandelwal, B. K. Kanaujia, S. Dwari, S. Kumar, and A. K. Gautam, "Analysis and Design of Dual Band Compact Stacked Microstrip Patch Antenna with Defected Ground Structure for WLAN/WiMAX Applications," Int. J. Electron. Commun. (AEU), vol. 69, no. 1, pp. 39-47, 2015. doi: https://doi.org/10.1016/j.aeue.2014.07.018.

[29] C. -M. Wu, C. -N. Chiu, and C. -K Hsu, "A New Non-Uniform Meandered and Fork-Type Grounded Antenna for Triple-Band WLAN Applications," IEEE Antennas Wirel. Propag. Lett., vol. 5, pp. 346-348, 2006. doi: 10.1109/LAWP.2006.880692.

[30] L. Peng, C. -L. Ruan, and X. -H. Wu, "Design and operation of dual/triple-band asymmetric M-shaped microstrip patch antennas," IEEE Antennas Wirel. Propag. Lett., vol. 9, pp. 1069-1072, 2010. doi: 10.1109/LAWP.2010.2091671.

[31] H. -X. Xu, G. -M. Wang, and M. -Q. Qi, "A Miniaturized Triple-Band Metamaterial Antenna with Radiation Pattern Selectivity And Polarization Diversity," Prog. Electromagn. Res., vol. 137, pp. 275-292, 2013. doi: 10.2528/PIER12081008.

[32] H. -X. Xu, G. -M. Wang, Y. -Y. Lv, M. -Q. Qi, X. Gao, and S. Ge, "Multifrequency Monopole Antennas by Loading Metamaterial Transmission Lines with Dual-Shunt Branch Circuit", Prog. Electromagn. Res., vol. 137, pp. 703-725, 2013. doi: 10.2528/PIER12122409.

[33] C. -T. Chuang, and S. -J. Chung, "Synthesis and Design of a New Printed Filtering Antenna," IEEE Trans. Antennas Propag., vol. 59, no. 3, pp. 1036-1042, 2011. doi: 10.1109/TAP.2010.2103001.

[34] W. Cheng, "Compact 2.4-GHz filtering monopole antenna based on modified SRR-inspired high-frequency-selective filter," Optik, vol. 127, pp. 10653-10658, 2016. doi: https://doi.org/10.1016/j.ijleo.2016.08.086.

[35] Z. H. Jiang, M. D. Gregory, and D. H. Werner, "Design and Experimental Investigation of a Compact Circularly Polarized Integrated Filtering Antenna for Wearable Biotelemetric Devices,” IEEE Trans. Biomed. Circuits. Syst., vol. 10, no. 2, pp. 328-338, 2016. doi: 10.1109/TBCAS.2015.2438551.

[36] A. Pirooj, M. N. -Moghadasi, and F. B. Zarrabi, "Design of Compact Slot Antenna Based on Split Ring Resonator for 2.45/5 GHz WLAN Applications With Circular Polarization,” Microw. Opt. Technol. Lett., vol. 58, no. 1, pp. 12-16, 2016. doi: $10.1002 /$ mop. 29484 .

[37] C. -T. Chuang, and S. -J. Chung, "A Compact Printed Filtering Antenna Using a Ground-Intruded Coupled Line Resonator,” IEEE Trans. Antennas Propag., vol. 59, no. 10, pp. 3630-3637, 2011. doi: 10.1109/TAP.2011.2163777.

[38] M. J. Duarte, V. P. da Silva Neto, and A. G. D’Assunção, "Synthesis and Mechanical Reconfiguration of Ground Plane Tilted Microstrip Antennas Based on Tetra-Circle Fractals," J. Microw. Optoelectron. Electromagn. Appl., vol. 19, no. 2, pp. 228-241, 2020. doi: 10.1590/2179-10742020v19i2838. 